\title{
Underlying mechanisms and drug intervention strategies for the tumour microenvironment
}

\author{
Haoze Li ${ }^{1,2}$, Lihong Zhou ${ }^{1,2}$, Jing Zhou ${ }^{1,2}, \mathrm{Qi} \mathrm{Li}^{1,2^{*}}$ and Qing $\mathrm{Ji}^{1,2^{*}}$
}

\begin{abstract}
Cancer occurs in a complex tissue environment, and its progression depends largely on the tumour microenvironment (TME). The TME has a highly complex and comprehensive system accompanied by dynamic changes and special biological characteristics, such as hypoxia, nutrient deficiency, inflammation, immunosuppression and cytokine production. In addition, a large number of cancer-associated biomolecules and signalling pathways are involved in the above bioprocesses. This paper reviews our understanding of the TME and describes its biological and molecular characterization in different stages of cancer development. Furthermore, we discuss in detail the intervention strategies for the critical points of the TME, including chemotherapy, targeted therapy, immunotherapy, natural products from traditional Chinese medicine, combined drug therapy, etc., providing a scientific basis for cancer therapy from the perspective of key molecular targets in the TME.
\end{abstract}

Keywords: TME, Cancer development, Molecular targets, Drug intervention strategies

\section{Background}

Cancer has been a difficult problem worldwide. In the United States, the overall 5-year relative survival rate of all cancers diagnosed between 2009 and 2015 is 67\%, and the United States is expected to have 1,806,590 new cancer cases and 606,520 cancer deaths in 2020 [1]. Therefore, to effectively treat cancer and prevent cancer recurrence and metastasis, researchers have studied its treatment for a long time. Presently, the main cancer treatment strategies include surgery, chemotherapy, radiotherapy, targeting therapy, immunotherapy, traditional Chinese medicine, etc., but their effects are not satisfactory. For example, the five-year recurrence-free survival rate of adenocarcinoma is 30\% [2]. In addition, although the clinical efficacy of gemcitabine ${ }^{+} \mathrm{NAB}^{-}$paclitaxel and other multi-drug regimens in the treatment of

\footnotetext{
* Correspondence: ttt99118@hotmail.com; qili@shutcm.edu.cn

'Department of Medical Oncology and Cancer Institute, Shuguang Hospital, Shanghai University of Traditional Chinese Medicine, Shanghai 201203, China Full list of author information is available at the end of the article
}

pancreatic cancer has been improved, it has not reached a satisfactory level [3]. Based on this, researchers not only pay attention to the treatment of cancer itself but also gradually try to change the TME through different strategies to indirectly achieve cancer treatment.

Currently, cancer treatment strategies targeting the TME are mainly focused on different molecular targets, special cells or intercellular ingredients in the TME through the related effects of chemotherapy, targeted therapy, immunotherapy, traditional Chinese medicine and even nanotechnology on TME to inhibit the promoting effect of the TME on cancer occurrence, development and metastasis. Cancer not only occurs in a complex tissue environment but also depends on the continuous spread, invasion and migration of the tissue environment.

The TME originates from the idea of "seed and soil" proposed by Stephen Paget, which holds that metastasis depends on the interaction between the "seed" (cancer cell) and "soil" (host microenvironment) [4]. Similarly, 
evidence has shown that primary cancers can induce secondary organs to gradually form a supportive microenvironment called the pre-metastatic niche [5]. Therefore, the TME is one of the key factors that affect cancer metastasis and growth.

As the importance of the TME to cancer development and metastasis is gradually known, the prevention and treatment of cancer through targeting the TME has become a research hotspot. In this paper, we reviewed our understanding of the TME, described its biological and molecular characteristics at different stages of cancer development, and discussed in detail the intervention strategies of key points of the TME, hoping to provide a scientific basis for cancer treatment from the perspective of the TME.

\section{Critical links and mechanisms of the TME}

In 1993, Anderson and Whitesid formally proposed the concept of the "TME" [6], indicating that the TME is the internal environment for the generation and life of cancer cells, which is mainly constituted by cancer cells, locally infiltrated immune cells, mesenchymal cells and their secreted active mediators, providing "fertile soil" for the proliferation, development, metastasis and other malignant biological behaviours of cancer cells. The TME is a complex system [7] that consists of the biological characteristics of hypoxia and low $\mathrm{pH}$, blood vessels, high permeability, inflammatory response and immunosuppression. Among them, cancer cells communicate with the microenvironment and interact with each other, resulting in a high degree of cell proliferation and metastasis [8]. Therefore, the TME is considered to be an important cause of cancer proliferation, invasion, migration, adhesion and neovascularization.

\section{Primary TME}

Generally, the TME is mainly composed of immune cells, vascular cells, fibroblasts, etc. Recruiting the above cells to the primary cancer site would construct a special TME and provide soluble paracrine signals to promote cancer progression (Fig. 1).

\section{Transcription factors}

High levels of inflammatory mediators are mainly caused by oncogene mutations and transcription factor activation. For example, mutation of the cancer suppressor gene p53 promotes the occurrence of cancer [9]. Mice expressing mutant p53 have more invasive and metastatic cancers than mice without p53 and are extremely prone to many types of cancers, including lung adenocarcinoma, squamous cell carcinoma, hepatocellular carcinoma, renal transitional cell carcinoma and colorectal cancer. Many of these cancers are invasive or show evidence of distant metastasis [10]. In addition, many types of p53 mutations in cancer cells produce resistance to anticancer drugs [11]. During tumorigenesis and progression, the important paracrine and autocrine factors are mainly cytokines and chemokines, which recruit and activate a variety of inflammatory cells in the TME [12]. The transcription factor STAT3 participates in the unique immunosuppressive pancreatic TME and pancreatic cancer progression in many ways through its activity in a variety of cell types, such as cancer cells and immune cells [13]. For example, in pancreatic cancer, the activation of STAT3 promotes the transformation of monocytes into monocyte-derived myeloid suppressor cells (MDSCs), thus participating in the immunosuppression of the pancreatic TME, affecting cancer stem cells and promoting the interstitial characteristics of cancer cells [14]. In ovarian cancer, activation of STAT3 can induce macrophages to differentiate into the M2 phenotype [15]. STAT3 activity can inhibit the chemotaxis and activation of $\mathrm{CD}^{+} \mathrm{T}$ cells in melanoma and mediate the differentiation of inhibitory $\mathrm{T}$ regulatory (Treg) cells, thus promoting cancer progression [16]. In addition, in solid cancers such as lung cancer, pancreatic cancer and intrahepatic cholangiocarcinoma, cancerassociated fibroblasts (CAFs) use STAT3 activity to secrete cytokines. These cytokines can recruit additional immune cells and promote STAT3 activity in other types of cells in the TME $[17,18]$.

\section{Stromal cells}

In the TME, stromal cells play crucial roles in initiating and maintaining chronic angiogenesis. Cancer endothelial cells can release specific growth factors, called vascular secretory factors [19]. Endothelial cells can change existing blood vessels or form new vascular networks to regulate the supply of nutrients and oxygen to cancer, and participate in communication between surrounding areas and cancer cells through paracrine and paracrine signals [20, 21].

Tumour-associated macrophages (TAMs) secrete proangiogenic factors to activate endothelial cells [22]. At the same time, neutrophils enter the TME and play various biological functions, including promoting cancer angiogenesis and cancer cell proliferation [23, 24]. On the other hand, cancer may induce fibroblasts and macrophages in the TME to acquire tumourigenic function. For instance, TAMs support a variety of primary cancer phenotypes by releasing a large number of cytokines, growth factors and carcinogenic proteases to participate in paracrine signalling circulation. In colorectal cancer, TAMs activate the IL-6/STAT3/miR-204-5p pathway by secreting IL-6, which supports cancer progression, increases the resistance of colorectal cancer to chemotherapeutic drugs and reduces drug-induced apoptosis [25]. Cancer-associated fibroblasts CAFs can activate cancer- 


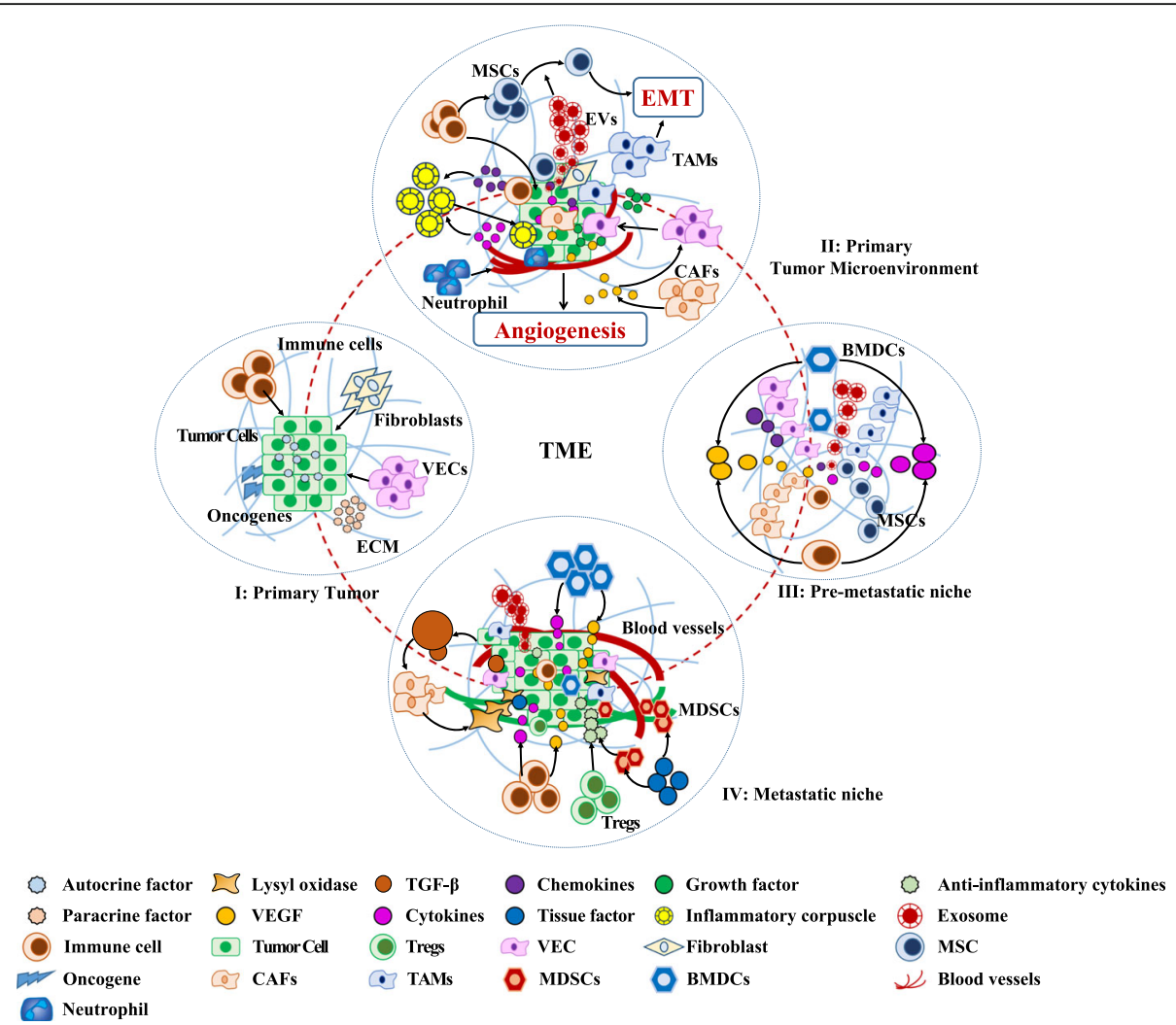

Fig. 1 Multiple stages of the TME in cancer progression. (I) TME in the budding stage of primary cancer: Oncogene activation leads to the conversion of normal cells to cancer cells, accompanied by the initial microenvironment formation in primary cancer sites containing fibroblasts, immune cells, vascular endothelial cells (VECS), etc. (II) TME in the progressing stage of primary cancer: inflammatory cells (producing chemokines and cytokines), neutrophils, tumour-associated macrophages (TAMs, producing carcinogenic proteases, cytokines and growth factors, and angiogenic factors), VECS, cancer-associated fibroblasts (CAFs, producing vascular endothelial growth factor, VEGF), extracellular matrix (ECM), etc. (III) Pre-metastatic niche: macrophages, platelets, mesenchymal stem cells, bone marrow-derived dendritic cells (BMDCs), immune cells (producing inflammatory cytokines, growth factors and angiogenic factors), etc. (IV) Metastatic niche: myeloid-derived suppressor cells (MDSCs, producing tissue factors and anti-inflammatory cytokines), Treg cells (producing anti-inflammatory cytokines), CAFs (producing transforming growth factor-1), etc.

derived factors, such as fibroblast growth factor (FGF), platelet-derived growth factor (PDGF) and transforming growth factor (TGF), and excrete basement membrane components and extracellular matrix proteins. Moreover, CAFs can also secrete vascular endothelial growth factor (VEGF) to support angiogenesis [26]. Cancer inflammation-related fibroblasts in bladder cancer produce VEGF, including VEGFA and VEGFB, which bind to VEGF receptors (FLT1, KDR, MET and FLT4) on endothelial cells, promote angiogenesis, affect the proliferation of cancer cells and stromal cells, and may recruit immune cells into the cancer stage [27].

\section{Extracellular matrix}

The cancer-associated extracellular matrix (ECM) has obvious differences in the composition and number of different constituents (i.e., proteoglycans, glycoproteins, proteins, and polysaccharides) in contrast to the ECM in normal tissues. Some studies have shown that the reciprocity between cancer extracellular matrix and normal breast tissue cells results in information interchange and sustained overexpression of cancer-specific genes [28]. Likewise, extracellular matrix components, including hyaluronic acid, collagen, fibronectin and laminin, cause ECM refactoring in the primary site of breast cancer through the interaction between cancer cells and extracellular matrix components [29]. Chemokines suppress cancer immunity by regulating the recruitment of Treg cells into the TME, thus supporting cancer initiation, progression and metastasis [30].

Studies have shown that the activation of hepatic stellate cells (HSCs) can secrete angiopoietin-1 (ANG-1), thereby promoting angiogenesis in hepatocellular carcinoma [31]. The functions of some components in the extracellular matrix may be similar, such as targeting cancer blood vessels or cancer cells; therefore, it is of clinical significance to counter the components in the extracellular matrix. 


\section{Extracellular vesicles}

Extracellular vesicles (EVs), including exosomes, can regulate many aspects of cancer biology. Many cancer or immune cell-derived EVs are involved in the entire process of cancer progression, such as angiogenesis, metastasis, immunity and resistance to anticancer treatments [32-34]. More specifically, Cianciaruso et al. detected that TAMs produce many EVs and affect the biological behaviour of other types of cells in the TME, which may be achieved through EVs fusion or membrane contact and functional molecular metastasis [35]. Our group confirmed that the primary cancer releases ITGBL1 (integrin $\beta 1$ )-enriched EVs and promotes the growth of distal metastatic cancers through the formation of a fibroblast niche. Specifically, in a colorectal cancer (CRC) model, the primary cancer releases ITGBL1-enriched EVs to activate fibroblasts in distant organs, promote the secretion of the pro-inflammatory cytokines to induce the constitution of pre-metastatic niche or facilitate the progression of metastatic neoplasms [36].

\section{Others}

Interestingly, the consumption of L-arginine in the TME controls the $\mathrm{T}$ cell immune response, and the $\mathrm{T}$ cell immune response is the basic mechanism of cancer cell immune escape [37]. Extracellular characteristics also contribute to cancer progression, such as high tissue hydraulic pressure, low partial pressure of oxygen, or changes in specific components of the extracellular matrix. In addition, a hypoxic TME is one of the common features of solid cancers. Exosomes mediate extensive bi-directional signal transduction among various cell types (cancer cells-cancer cells, cancer cells-stromal cells and stromal cells-stromal cells) in the hypoxic TME. They are considered to regulate hypoxia adaptation and reconstruct the microenvironment in return [38]. In lung cancer, plasma exosomes secreted by hypoxemic BMSCs can promote the invasion of lung cancer cells by activating the STAT3 signalling and EMT [39]. The TME contains leaky and constricted blood vessels, characterized by hypoxia and acidosis, allowing cancer cells to promote angiogenesis, connective tissue proliferation, and inflammation without control, leading to a vicious cycle that promotes disease progression [40]. The anoxic microenvironment is beneficial to glycolysis and lactic acid production of key enzymes of glycolysis and lactate dehydrogenase A (LDH-A). Excessive production of lactic acid leads to an acidic $\mathrm{pH}$ promoting cancer metastasis [41].

\section{Pre-metastatic niche}

Before cancer cell metastasis, primary focal cancer cells can secrete a variety of cytokines in remote organs, affecting and changing the formation of the organ metastasis microenvironment (pre-metastatic niche) (Fig. 1). It is worth noting that all events that adjust the formation of the niche before metastasis are deemed to occur before the cancer cells reach the niche. Cancer cells prepare and form pre-metastatic niches in distal organs, which refer to the arrangement of pre-metastatic signals, including exosomes, growth factors, cytokines, etc., to regulate their position before cancer metastasis.

\section{Exosomes}

Exosomes are a subclass of extracellular vesicles that participate in cell-cell communication. The exosomes secreted by stromal and cancer cells can not only regulate cancer progression in the primary TME but also help the formation of a pre-metastatic inflammatory niche [42]. Exosomes containing various proteins, miRNAs and mRNAs can promote the formation of a premetastatic niche either by mediating the relationship between surrounding components and cancer cells or by diverting their contents to recipient cells [43]. Wortzel et al. found that these exosomes remodel the TME and boost cancer growth by delivering active molecules and RNA to other cells [44]. Exosomal miR-21 promotes liver metastasis by activating macrophages to form proinflammatory phenotypes, thus forming pre-metastatic inflammatory niches [45].

\section{Stromal cells}

Through the regulation of stromal cells in secondary organs, the microenvironment of metastatic cancer is formed, and the immune response, inflammation, angiogenesis, matrix remodelling and organ tendency of cancer cell metastasis are regulated [46]. Song et al. confirmed that the peritoneal macrophages are closely related to peritoneal metastasis of gastric cancer. In detail, peritoneal macrophages support angiogenesis and cancer growth through the production of vascular endothelial growth factor (VEGF) and epidermal growth factor (EGF) [47]. Similarly, CAFs-derived hydrogen peroxide-induced clone 5 (HIC-5) regulates cytokines and modifies the ECM to regulate the invasion of oesophageal squamous cell carcinoma (ESCC) cells [48].

\section{Epithelial-mesenchymal transition}

The course of epithelial-mesenchymal transition (EMT) promotes the spread of cancer [49]. Macrophages, platelets and mesenchymal stem cells (MSCs) can promote the EMT, separate cancer cells from contact with neighbouring epithelial cells and acquire motor/invasive phenotypes [26]. The basement membrane and the stroma are degraded and invaded by the EMT, which can cause cancer cells to enter circulation through lymphatic or blood pathways, secrete growth factors and cytokines, 
and survive under the protective interaction between them and platelets [50]. When the cancer cells remain in the narrow capillaries of the target organs, the cancer cells can destroy the endothelial cell connection, infiltrate the surrounding tissue, and maintain the initial dormant state until the conditions are conducive to the colonization of metastasis [51]. In addition, the EMT can promote the differentiation of cancer cells into cancer stem cells [52]. In the TME, immune cells and stromal cells, such as TA-MSCs and CAFs, are considered to constitute the microenvironment of cancer stem cells, which regulate the fate of cancer stem cells by providing signals composed of cell-cell contact and the secretion of factors (growth factors and cytokines that promote CSC self-renewal) [53].Foe example, STAT3 is induced by IL-6 and other inflammatory factors [54]. Moreover, the interaction between cancer stem cells and the TME promotes cancer progression; for example, glioma stem cells (GSCs) can preferentially secrete Wnt-induced signal protein 1 (WISP1) and promote the development of the TME by promoting the survival of GSCs and TAMs through WISP1 [55]. In addition, in all types of cancers, CSCs showed changes in energy balance and metabolic status, such as enhanced glycolysis, compared with nonCSCs [56]. Therefore, in the TME, the metabolic changes induced by inflammation may be involved in the formation of CSCs and carcinogenesis.

\section{Promotion factors or stromal components}

The pre-metastatic niche is established and initiated via the intricate interaction among local matrix components, primary cancer-derived factors and cancermobilized bone marrow-derived cells [5]. For example, in a mouse model of lung metastasis, MDSCs are a key factor in the formation of the microenvironment before metastasis after the resection of the primary cancer [57]. More specifically, the pre-metastatic niche is established by recruited bone marrow-derived cells (BMDCs) and immune cells. These cells can secrete growth factors, inflammatory cytokines and angiogenic molecules to reshape the local microenvironment and support cancer cell invasion, colonization and proliferation [58].

\section{Extracellular matrix}

Treg cells, cancer-associated neutrophils, MDSCs and TAMs can be recruited to secondary organs by cancer cell-derived cytokines and chemokines, and facilitate metastasis by supporting the development of premetastatic niches [59]. CXCR4/TGF- $\beta 1$ can boost the liver metastasis of colon cancer by mediating the differentiation of HSCs into CAFs [60].

In addition, in the secondary sites of breast cancer (lungs), lysyl oxidase, periostin and tenascin $\mathrm{C}$, together with the pro-metastatic molecules Coco and $\mathrm{N}$ - acetylgalactosamine transferase 14 (GALNT14), promote lung metastatic cell colonization and ECM remodelling, resulting in the formation of a pre-metastatic niche (PMN) [29]. Du et al. discovered that the combination of mesenchymal stem cell-derived interleukin (IL)-8 and $\mathrm{C}-\mathrm{X}-\mathrm{C}$ chemokine receptor (CXCR)-1 promotes osteosarcoma cell anoikis resistance and lung metastasis by activating the Akt signalling pathway [61]. The hypoxic state of the TME increases the recruitment of Tregs by inducing the expression of chemokine CC-chemokine ligand 28 (CCL28), which promotes the immunosuppression of the TME [62]. In addition, cancer hypoxia hinders the function of MDSCs in the TME through HIF- $1 \alpha$ and turnstheir differentiation state into TAMs [63].

\section{Adenosine-triphosphate}

The change of adenosine triphosphate in the PMN is also a key point of cancer metastasis. Li et al. confirmed that one of the reasons for the promotion of the metastasis of cancer cells is the higher concentration of extracellular ATP in cancer tissue than in normal tissue [64]. The main mechanism by which extracellular ATP (eATP) promotes metastasis is to increase the concentration of intracellular free $\mathrm{Ca}^{2+}$, which promotes the release of several cytokines and triggers the EMT [65].

\section{Metastatic microenvironment}

Cancer stem cells and cancer cells exudate from the primary focus, infiltrate into the extracellular matrix, and promote angiogenesis or cell infiltration into the circulatory system, thus evading the host's defence mechanism through chemotaxis, causing it to migrate to specific vascular sites, adhere, and then exudate blood vessels and return to a specific environment until metastatic foci are formed (Fig. 1). Metastatic cancer cells usually reside in distal tissues and organs in a dormant state. The mechanism of controlling metastatic dormancy includes the regulation of the expression of genes in disseminated cancer cells (DTCs), including genetic and/or epigenetic control, as well as the regulation mechanism of the TME [66]. For example, the niche after liver metastasis, which develops after cancer cells enter the liver, can be divided into four key stages (i) microvascular, (ii) preangiogenesis, (iii) angiogenesis and (iv) growth stages [67].

\section{Stromal cells and the extracellular matrix}

Immunosuppressive cells are recruited into cancer to help establish a state of immunosuppression in secondary tissues. Treg cells and MDSCs secrete antiinflammatory cytokines, which inhibit the anti-cancer ability of immune cells. Once micrometastases overcome their dormancy, they receive signals and cells from the 
microenvironment to further support their invasion. For example, the coagulation system and components of platelets, such as tissue factor (TF), are crucial mediators of metastatic growth, which can interfere with NK cells to undermine micrometastases or support clot formation, leading to the recruitment of MDSCs [26]. In the lung metastasis of breast cancer, IL- $1 \alpha$ and IL- $1 \beta$ secreted by breast cancer cells induce the production of CXCL9 and CXCL10 in lung fibroblasts through NF-kB signal transduction, thus promoting the growth of lung metastasis [68]. Li et al. found that CAFs-derived lysyl oxidase (LOX) in liver metastases of gastric cancer promotes niche formation and growth, indicating a poor prognosis. In the meantime, cancer cells secrete transforming growth factor- $\beta-1$ to nourish CAFs and stimulate them to produce more lysyl oxidase [69]. In addition, the metabolism of CAFs also undergoes fundamental changes during the activation process. For example, CAFs use aerobic glycolysis to maintain the enhanced proliferative activity of cancer cells rather than relying on oxidative phosphorylation (OXPHOS) [70]. CAFs use carbon from different sources to produce glutamine for cancer cells to promote ovarian cancer progression [71]. CAFs also play important roles in drug resistance. CAFs can cause drug resistance by providing a protective environment for cancer cells [72]. The cancer interstitial pressure it produces also limits the entry of drugs into cancer cells and indirectly induces drug resistance [73].

\section{Characteristics of metastatic organs}

The microenvironments of different metastatic organs of cancer have their own characteristics. Kaplan et al. demonstrated that resident fibroblasts in secondary organs can help primary cancer upregulate the expression of fibronectin. These fibroblasts are also the junction of the VEGFR $1^{+}$ haematopoietic progenitor cell (HPC) cluster and migratory cancer cells [74]. Further research on the role of secretory factors in maintaining and overcoming dormancy comes from screening metastatic breast cancer. Interestingly, Gao et al. showed that some signals work only in the lungs not in the bone and brain, suggesting that metastasis-initiating cells can cover microenvironment-mediated inhibition in an organ-specific way [75]. On the other hand, Yoshikawa et al. found that M2-polarized macrophages in peripheral blood are related to the construction and growth of liver metastases in patients with pancreatic cancer [76]. Therefore, the special characteristics of the microenvironment of metastatic organs are also a valuable research direction.

\section{Mechanism of drug resistance mediated by TME}

The TME is also a protective barrier for cancers. The interaction between cancer cells and the TME enables some cancer cells to escape apoptosis and develop drug resistance. Microenvironment-mediated drug resistance may be caused by the adhesion of cancer cells to interstitial fibroblasts or extracellular matrix components, or by soluble factors secreted by stromal cells, or mediated by the immune response [77]. For example, stromal cells from lymph nodes promote resistance to 5-fluorouracil and oxaliplatin through SDF1/CXCR4-dependent mechanisms [78]. Studies on melanoma have also confirmed that CAFs promote the metastasis and drug resistance of melanoma cells by increasing the expression of MMP1 and MMP2 [79]. Gemcitabine and 5-fluorouracil can activate MDSCs, and induce the production of IL-1 $\beta$, which induces the Th17 response and weakens the anticancer effect [80]. Therefore, taking the TME as the target may destroy the interaction between the TME and cancer cells and make follow-up treatment more effective.

\section{Liquid TME}

The liquid TME is mainly formed by the interaction between haematopoietic cancer cells and stromal cells, such as B-cell lymphoma, including follicular lymphoma (FL), mantle cell lymphoma (MCL), chronic lymphocytic leukaemia (CLL), classical Hodgkin's lymphoma (CHL) and mucosa-associated lymphoid tissue lymphoma (MALT), providing striking examples of a pivotal interaction of haematopoietic cancer cells with stromal cells [81]. The important components of its microenvironment are monocyte-derived milk cells (NLCs), mesenchymal stromal cells, $\mathrm{T}$ cells and NK cells, which communicate with cancer cells through a complex network of adhesion molecules, chemokine receptors, cancer necrosis factor (TNF) family members and soluble factors [82]. Unlike solid cancers, some of these cell types and precursors were already present in secondary lymphoid organs before the onset of lymphoma [83]. For example, the specialized fibroblast reticular cells (FRCs) that make up the trunk of SLOs are essential for organ development and the division of $\mathrm{T}$ and $\mathrm{B}$ cell regions and participate in the acquired immune response [84]. There is a great difference between liquid cancers and solid cancers, and the mechanisms of their microenvironment and components are very different. For example, there is a detailed understanding of TAMs in solid cancers, but the mechanism of TAMs in liquid cancers is not well understood [85]. Through the study of the solid TME, we can provide some new ideas for the study of the liquid TME.

\section{Microenvironment-specific interventions}

Currently, the TME is the focus of cancer metastasis and growth research. Many intervention strategies are applied to change the TME, including chemotherapy, targeted therapy, immunotherapy, nanoparticle systems, 
traditional Chinese medicine, and combined drug therapy (see Table 1). Moreover, many drugs for the treatment of the TME (monotherapy or combination therapy) have entered the clinical trial stage and are actively recruiting patients (Table 2).

\section{Chemotherapy drugs for the TME}

Chemotherapeutic drugs, also known as cytotoxic drugs, usually have anti-cancer effects by acting on key cellular biological events necessary for cancer cell survival and proliferation. Their effects on various components in the TME have become a research point (Fig. 2).

Chemotherapy can activate the local immune state, which regulates the anti-cancer $\mathrm{T}$ cell response by enhancing the effector $\mathrm{T}$ cell response, disrupting the immunosuppressive pathway and increasing cancer antigenicity [86-88]. By comparing the therapeutic effects of 27 patients with osteosarcoma before and after treatment, neoadjuvant chemotherapy was related to an the increase in the density of $\mathrm{CD}^{+} \mathrm{T}$ cells, $\mathrm{CD}^{+} \mathrm{T}$ cells, $\mathrm{Ki} 67^{+} \mathrm{CD}^{+} \mathrm{T}$ cells and PD- $\mathrm{L}^{+}$immune cells, and the myeloid suppressor cells of HLA-DR-CD33 ${ }^{+}$decreased significantly after treatment [89]. Oxaliplatin (OXP) alone can eliminate immunosuppressive cells, suppress cancer growth and induce an anti-cancer immunostimulatory microenvironment. For example, for the model of the abdominal metastasis of colon cancer, the administration of OXP can increase cancer infiltration and activation of $\mathrm{CD}^{+} \mathrm{T}$ cells, reduce cancer $\mathrm{CD} 11 \mathrm{~b}^{+} \mathrm{F} 4 / 80^{\text {high }}$ macrophages, and reduce spleen MDSCs, thus affecting the cancer immune microenvironment [125].

Through preclinical studies and phase I clinical trials of four patients with advanced solid cancers (thyroid cancer, colon cancer, pancreatic cancer and melanoma), Winterhoff et al. found that PG545 suppresses growth factor-mediated cell invasion; reduces the phosphorylation of AKT, EGFR and ERK induced by HB-EGF; and significantly abates the cancer burden, which is strengthened when combined with carboplatin in the SKOV-3 model or paclitaxel in the A2780 model [90]. In a mouse model of pancreatic ductal adenocarcinoma (PDAC), gemcitabine (GEM) or paclitaxel (PTX) could inhibit EMT, to reduce the frequency of CTCs and the logarithm of CTCs in circulating cancer cells, thus reducing cancer metastasis [91].

There is no doubt about the status of chemotherapy as the earliest treatment for cancer. In the model of brain metastasis of breast cancer, fludarabine is highly selective for cells with low expression of X-inactivated specific transcript (XIST), which significantly inhibits the growth of brain cancer cells, delays the occurrence of brain metastasis, and has no obvious toxicity [92]. Chemotherapy has its own advantages, but patients have poor tolerance and strong drug resistance. It may affect the TME to promote the spread of cancer cells to secondary sites [93]. Therefore, how to reduce the side effects of chemotherapy in microenvironment treatment in clinical practice may be of great concern.

\section{Targeted drugs for the TME}

The TME is complex and diverse, in which various components and characteristics are closely related to cancer occurrence and development, and thus, targeted regulation of components or signalling pathways in the TME has become the key to suppressing cancer proliferation and invasion (Fig. 3). For instance, Shao et al. confirmed that rapamycin-mediated autophagy can result in a reduction in the expression of Bcl-2 and survivin and an increase in the expression of Smac in TAMs. The upregulation of TAM autophagy inhibits the propagation of colon cancer cells, induces apoptosis, and changes the expression of radiosensitivity-related proteins [94].

The same drug may have an effect on different targets in the microenvironment of different types of cancers. For example, in a mouse model of human hepatocellular carcinoma xenotransplantation, apatinib can effectively reduce cancer angiogenesis, inhibit cancer growth and prolong animal survival [95]. In an osteosarcoma model, apatinib suppresses the invasion and migration of cancer cells and the expression of PD-L1 by targeting STAT3 to inhibit the EMT. Interestingly, it can also block the PI3K/AKT and VEGFR2/RAF/MEK/ERK signalling pathways in cholangiocarcinoma cells, thus affecting VEGF-mediated cell proliferation and invasion [126]. This suggests that the existing targeted drugs may have greater potential and are worthy of our study.

Different targets in the microenvironment of the same cancer type are often affected by different drugs to inhibit cancer proliferation and metastasis. In experimental mouse models of breast cancer, WRG-28 inhibits cancer invasion and migration by targeting DDR2, reduces the supporting effect of the matrix on cancer, and thus inhibits the colonization of metastatic breast cancer cells in the lungs [127]. Lee et al. screened 51 drugs that are in clinical trials or approved by the FDA and found that bortezomib (BTZ) and phenobarbital (PST) can reduce the survival rate of CAFs by inducing caspase-3mediated apoptosis and inhibit the proliferation of cancer cells in a breast cancer mouse transplantation model [96]. In addition, Uriesalgo et al. showed that targeting apelin with apelin inhibitors can inhibit angiogenesis and growth in breast and lung cancer models without increasing TME hypoxia, improve vascular function, and reduce the infiltration of polymorphonuclear myeloid derived suppressor cells [97]. Therefore, the synergistic effect of different targeted drugs on the TME can be considered for the prevention and treatment of cancer. 
Table 1 Comprehensive list of drugs for the TME and their mechanisms of action

\begin{tabular}{|c|c|c|c|c|}
\hline Drug & Inhibitory mechanisms & Mode of action & Test mode & Reference \\
\hline Oxaliplatin & Immunosuppressive cells & $\begin{array}{l}\text { Increase activation of CD8 + T cells, reduce cancer CD11b + } \\
\text { F4/80 high macrophages, and reduce spleen MDSCs }\end{array}$ & $\begin{array}{l}\text { In vitro and } \\
\text { in vivo test }\end{array}$ & [86] \\
\hline PG545 & $\begin{array}{l}\text { Growth factor-mediated } \\
\text { cell invasion }\end{array}$ & $\begin{array}{l}\text { Reduces the phosphorylation of AKT, EGFR and ERK } \\
\text { induced by HB-EGF }\end{array}$ & $\begin{array}{l}\text { Phase I } \\
\text { clinical trials }\end{array}$ & [87] \\
\hline Gemcitabine & EMT & Reduce the frequency of CTC and the logarithm of CTC & $\begin{array}{l}\text { In vitro and } \\
\text { in vivo test }\end{array}$ & [88] \\
\hline Paclitaxel & EMT & Reduce the frequency of CTC and the logarithm of CTC & $\begin{array}{l}\text { In vitro and } \\
\text { in vivo test }\end{array}$ & [88] \\
\hline Fludarabine & Brain cancer cells & X-inactivated specific transcript & $\begin{array}{l}\text { In vitro and } \\
\text { in vivo test }\end{array}$ & [89] \\
\hline Rapamycin & TAMs & $\begin{array}{l}\text { Reduction in the expression of } \mathrm{Bcl}-2 \text { and Survivin and an in- } \\
\text { crease in the expression of Smac }\end{array}$ & In vitro test & [90] \\
\hline Apatinib & EMT/Angiogenesis & $\begin{array}{l}\text { Targeting STAT3/block PI3K/AKT and VEGFR2/RAF/MEK/ERK } \\
\text { signaling pathways }\end{array}$ & $\begin{array}{l}\text { In vitro and } \\
\text { in vivo test }\end{array}$ & {$[91,92]$} \\
\hline WRG-28 & $\begin{array}{l}\text { Cancer invasion and } \\
\text { migration }\end{array}$ & DDR2 & $\begin{array}{l}\text { In vitro and } \\
\text { in vivo test }\end{array}$ & [93] \\
\hline Bortezomib & CAF & Caspase-3 & $\begin{array}{l}\text { In vitro and } \\
\text { in vivo test }\end{array}$ & [94] \\
\hline Pambarbital & CAF & Caspase-3 & $\begin{array}{l}\text { In vitro and } \\
\text { in vivo test }\end{array}$ & [94] \\
\hline Apelin inhibitor & Angiogenesis/MDSCs & Apelin & $\begin{array}{l}\text { In vitro and } \\
\text { in vivo test }\end{array}$ & [95] \\
\hline Dasatinib & TAMS & Inhibited the self-renewal ability of H460R and A549R cells & In vitro test & [96] \\
\hline Repagenil & Cancer cell & MSCs & $\begin{array}{l}\text { In vitro and } \\
\text { in vivo test }\end{array}$ & [97] \\
\hline Anti-CTLA-4 antibody & T cells & $\begin{array}{l}\text { Enhance antibody-dependent cell-mediated cytotoxicity, } \\
\text { phagocytosis }\end{array}$ & $\begin{array}{l}\text { Preclinical } \\
\text { trial }\end{array}$ & [98] \\
\hline $\begin{array}{l}\text { Transforming growth factor- } \beta \\
\text { inhibitors }\end{array}$ & $\begin{array}{l}\text { Cancer cell/releasing } \\
\text { cytotoxic T cells/promote } \\
\text { T cell infiltration }\end{array}$ & Transforming growth factor- $\beta$ & $\begin{array}{l}\text { In vitro and } \\
\text { in vivo test }\end{array}$ & {$[99,100]$} \\
\hline Plerixafor & Angiogenesis & CXCR4 & $\begin{array}{l}\text { In vitro and } \\
\text { in vivo test }\end{array}$ & [101] \\
\hline $\begin{array}{l}\text { Macrophage receptor with } \\
\text { collagen structure }\end{array}$ & Cancer proliferation & E-programming of macrophages & $\begin{array}{l}\text { In vitro and } \\
\text { in vivo test }\end{array}$ & [102] \\
\hline Embeline & $\begin{array}{l}\text { Growth of pancreatic } \\
\text { cancer }\end{array}$ & $\begin{array}{l}\text { Increasing the infiltration of Th1 cells, NK, CTL, Y } \delta \text { T and } \\
\text { NKT, and reducing the infiltration of Th17, PMN-MDSC, IL-8 } \\
\text { and IL-6 positive immune cells }\end{array}$ & $\begin{array}{l}\text { In vitro and } \\
\text { in vivo test }\end{array}$ & [103] \\
\hline Functionalized micellar & $\begin{array}{l}\text { Reverse the abnormal } \\
\text { expression of several key } \\
\text { marker proteins }\end{array}$ & $\begin{array}{l}\text { Inhibit the adhesion of activated endothelial cells to } \\
\text { circulating cancer cell }\end{array}$ & $\begin{array}{l}\text { In vitro and } \\
\text { in vivo test }\end{array}$ & [104] \\
\hline $\begin{array}{l}\text { Cancer matrix-targeted nano- } \\
\text { carrier }\end{array}$ & $\begin{array}{l}\text { Cut off the support of the } \\
\text { matrix to cancer cells }\end{array}$ & Remove CAFs, & $\begin{array}{l}\text { In vitro and } \\
\text { in vivo test }\end{array}$ & [105] \\
\hline $\begin{array}{l}\text { Nanoparticles-based } \\
\text { photoimmunotherapy }\end{array}$ & T cells & CAFs & $\begin{array}{l}\text { In vitro and } \\
\text { in vivo test }\end{array}$ & [106] \\
\hline Curcumin & Cancer cells, Angiogenesis & $\begin{array}{l}\text { VEGF, IL- } 6 \text { and cancer stem cells, transcription factor nuclear } \\
\text { factor-NB (NF-NB), signal transduction, transcriptional activa- } \\
\text { tor } 3 \text { and angiogenic cytokines }\end{array}$ & $\begin{array}{l}\text { In vitro and } \\
\text { in vivo test }\end{array}$ & {$[107,108]$} \\
\hline APG-157 & $\begin{array}{l}\text { Attract immune cells into } \\
\text { the TME }\end{array}$ & $\begin{array}{l}\text { Increased expression of CD4+ and CD8+ cells and increased } \\
\text { expression of PD-1 and PD-L1 }\end{array}$ & $\begin{array}{l}\text { Phase I } \\
\text { placebo } \\
\text { controlled } \\
\text { trial }\end{array}$ & [109] \\
\hline Sophoridine & Macrophage & TLR4/IRF3 pathway & In vitro test & [110] \\
\hline Ginsenoside Rh2 & Improve TME & Regulating the phenotype of TAMs & $\begin{array}{l}\text { In vitro and } \\
\text { in vivo test }\end{array}$ & [111] \\
\hline
\end{tabular}


Table 1 Comprehensive list of drugs for the TME and their mechanisms of action (Continued)

\begin{tabular}{|c|c|c|c|c|}
\hline Drug & Inhibitory mechanisms & Mode of action & Test mode & Reference \\
\hline Berberine & EMT & $\begin{array}{l}\text { Smad-independent and Smad-dependent transforming } \\
\text { growth factor- } \beta \text { signaling pathway }\end{array}$ & In vitro test & [112] \\
\hline Wogonin & EMT & IL-6/STAT3 signal pathway & $\begin{array}{l}\text { In vitro and } \\
\text { in vivo test }\end{array}$ & [113] \\
\hline Bigelovin & EMT & $\mathrm{N}$-and E-cadherin, STAT3 pathway, and cofilin pathway & $\begin{array}{l}\text { In vitro and } \\
\text { in vivo test }\end{array}$ & [114] \\
\hline Cordycepin & $\begin{array}{l}\text { Up-regulating cancer cell } \\
\text { apoptosis and eliciting } \\
\text { cell cycle arrest }\end{array}$ & $\operatorname{CsCs}$ & In vitro test & [115] \\
\hline Shikonin & Cancer cell & Exosome & In vitro test & [116] \\
\hline 6-gingerol (6G) & TME & $\begin{array}{l}\text { Promoting cancer vascular normalization, reducing } \\
\text { microvascular structure entropy (MSE) }\end{array}$ & $\begin{array}{l}\text { In vitro and } \\
\text { in vivo test }\end{array}$ & [117] \\
\hline Salvianolic acid A & Angiogenesis & Block the secretion of glucose-regulated protein 78 & $\begin{array}{l}\text { In vitro and } \\
\text { in vivo test }\end{array}$ & [118] \\
\hline Dihydrodiosgenin & Inhibit HCC metastasis & $\begin{array}{l}\text { Inhibit platelet activation and reduce endothelial cell- } \\
\text { derived factor VIII }\end{array}$ & $\begin{array}{l}\text { In vitro and } \\
\text { in vivo test }\end{array}$ & [119] \\
\hline $\begin{array}{l}\text { Poly (adenosine diphosphate- } \\
\text { ribose) polymerase (PARP) } \\
\text { inhibitor (PARPI) }\end{array}$ & Up-regulate PD-L1 & Promoting the activation of IFN pathway, Up-regulate PD-L1 & $\begin{array}{l}\text { Preclinical } \\
\text { trial }\end{array}$ & {$[120,121]$} \\
\hline $\begin{array}{l}\text { The combination of PARPI and } \\
\text { mitogen-activated protein kin- } \\
\text { ase (MEK) inhibitor }\end{array}$ & TME & $\begin{array}{l}\text { Induces BIM-mediated apoptosis by activating caspase-3, in- } \\
\text { hibits the expression of CD } 31 \text { in endothelial cells, and in- } \\
\text { hibits the production of mutant RAS-induced VEGF through } \\
\text { RAS/MAPK pathway }\end{array}$ & $\begin{array}{l}\text { In vitro and } \\
\text { in vivo test }\end{array}$ & [122] \\
\hline $\begin{array}{l}\text { Sorafenib combined with } \\
\text { bufalin }\end{array}$ & Angiogenesis & mTOR/NEGF signal pathway & $\begin{array}{l}\text { In vitro and } \\
\text { in vivo test }\end{array}$ & [123] \\
\hline $\begin{array}{l}\text { Ginsenoside Rg3 combined with } \\
\text { cisplatin }\end{array}$ & TME & EMT & $\begin{array}{l}\text { In vitro and } \\
\text { in vivo test }\end{array}$ & [124] \\
\hline
\end{tabular}

Therapeutic and targeted delivery at the cancer site can be achieved by modifying exosomes with corresponding targeting ligands, for example, in mouse models of breast and ovarian cancer, DOX enhances its targeting through exosomes and effectively inhibits cancer progression [128]. The discovery of an antibodyfunctionalized exosome-targeting delivery system may be a new human cancer drug delivery system. In vivo experiments have shown that the A33 antibodyfunctionalized exocrine targeted delivery of doxorubicin

Table 2 Selective Actively Recruiting Clinical Trials for patients

\begin{tabular}{|c|c|c|c|c|c|}
\hline Name of study Clinical & Phase & Conditions & Therapy & Measure & Clinicaltrials.gov Identifier \\
\hline A Study of ALKS 4230 on the TME & $\begin{array}{l}\text { Phase } \\
2\end{array}$ & $\begin{array}{l}\text { Advanced Solid } \\
\text { cancer }\end{array}$ & $\begin{array}{l}\text { ALKS } 4230+ \\
\text { pembrolizumab }\end{array}$ & $\begin{array}{l}\text { Total T cells, CD8 }{ }^{+} \mathrm{T} \\
\text { cells, CD56 }{ }^{+} \text {cells and } \\
\text { Treg cells }\end{array}$ & NCT04592653 \\
\hline $\begin{array}{l}\text { Effects of MK-3475 (Pembrolizumab) on } \\
\text { the Breast TME in Triple Negative Breast } \\
\text { Cancer }\end{array}$ & & $\begin{array}{l}\text { Triple Negative Breast } \\
\text { Cancer }\end{array}$ & $\begin{array}{l}\text { Merck } 3475 \\
\text { Pembrolizumab }\end{array}$ & $\begin{array}{l}\text { Number of subjects } \\
\text { with significant mean } \\
\text { percent change in } \\
\text { TILs }\end{array}$ & NCT02977468 \\
\hline $\begin{array}{l}\text { Analysis of the Modulation of the TME by } \\
\text { MK-3475 (Pembrolizumab) Using a Sys- } \\
\text { tems Biology Approach (PEMSYS) }\end{array}$ & $\begin{array}{l}\text { Phase } \\
2\end{array}$ & $\begin{array}{l}\text { Metastatic Melanoma } \\
\text { Naive to Immune } \\
\text { Therapy in Metastatic } \\
\text { Setting }\end{array}$ & $\begin{array}{l}\text { Pembrolizumab - } \\
\text { additional } \\
\text { treatment }\end{array}$ & Bioinformatics & NCT03534635 \\
\hline $\begin{array}{l}\text { GVAX Pancreas Vaccine (With CY) in } \\
\text { Combination With Nivolumab and SBRT } \\
\text { for Patients With Borderline Resectable } \\
\text { Pancreatic Cancer }\end{array}$ & $\begin{array}{l}\text { Phase } \\
2\end{array}$ & Pancreatic Cancer & Cyclophosphamide & $\begin{array}{l}\text { CD8 count (cells/ } \\
m m \wedge 3 \text { ) in the TME }\end{array}$ & NCT03161379 \\
\hline $\begin{array}{l}\text { L-DOS47 Plus Doxorubicin in Advanced } \\
\text { Pancreatic Cancer }\end{array}$ & $\begin{array}{l}\text { Phase } \\
1 / \\
\text { Phase } \\
2\end{array}$ & Pancreas Cancer & $\begin{array}{l}\text { L-DOS47 Plus } \\
\text { Doxorubicin }\end{array}$ & $\begin{array}{l}\text { Cancer } \mathrm{pH} \text {, } \\
\text { Proportion of patients } \\
\text { expressing anti-L- } \\
\text { DOS47 antibodies }\end{array}$ & NCT04203641 \\
\hline
\end{tabular}




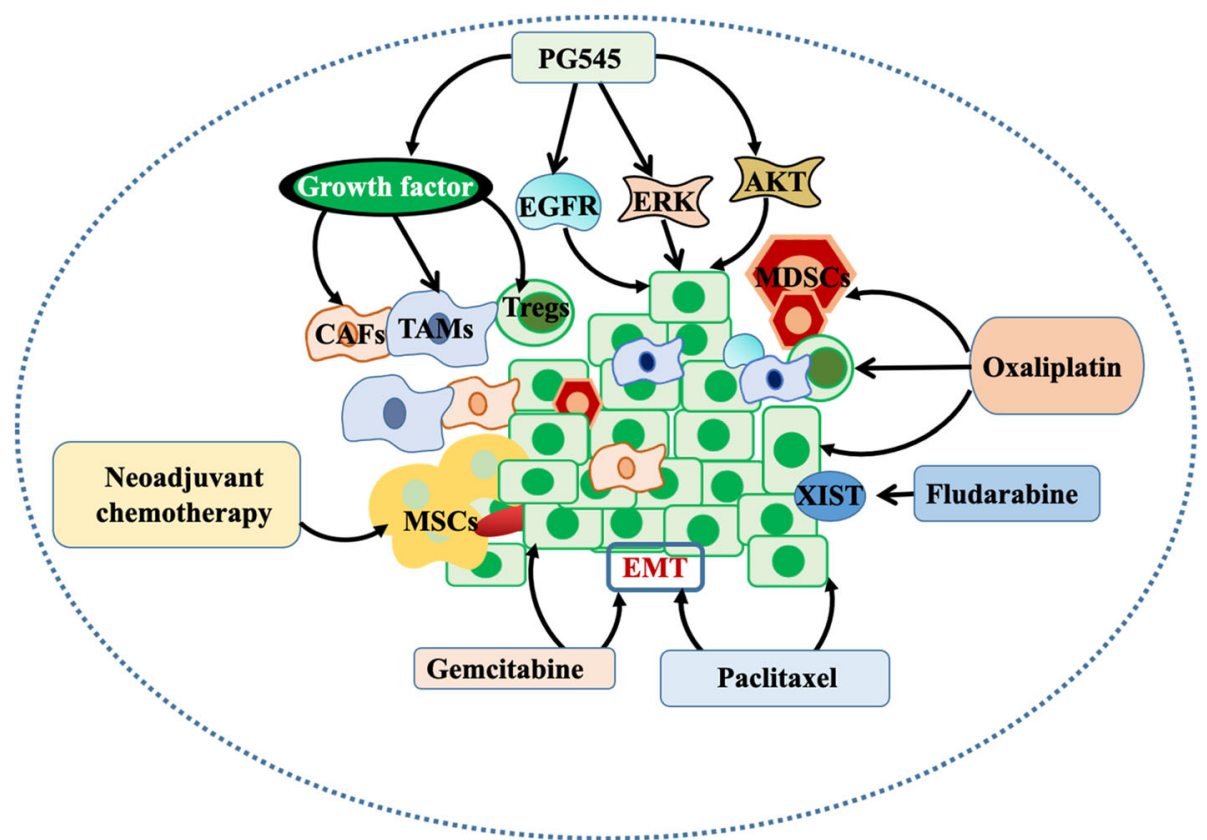

Fig. 2 Intervention of chemotherapy on the TME. Neoadjuvant chemotherapy can increase the density of myeloid suppressor cells. Oxaliplatin (OXP) can increase cancer infiltration and activation of $C D 8^{+} \mathrm{T}$ cells and reduce cancer CD11 b F $4 / 80^{\text {high }}$ macrophages and spleen MDSCs. PG545 inhibits growth factor-mediated cell invasion, reduces the HB-EGF-induced phosphorylation of AKT, EGFR and ERK, and reduces the cancer burden. Gemcitabine (GEM) or paclitaxel (PTX) inhibited the EMT by reducing the frequency of CTCs and the logarithm of CTCs. Fludarabine has high selectivity for cells with low expression of X-inactivated specific transcription (XIST) and inhibits the growth of brain cancer cells

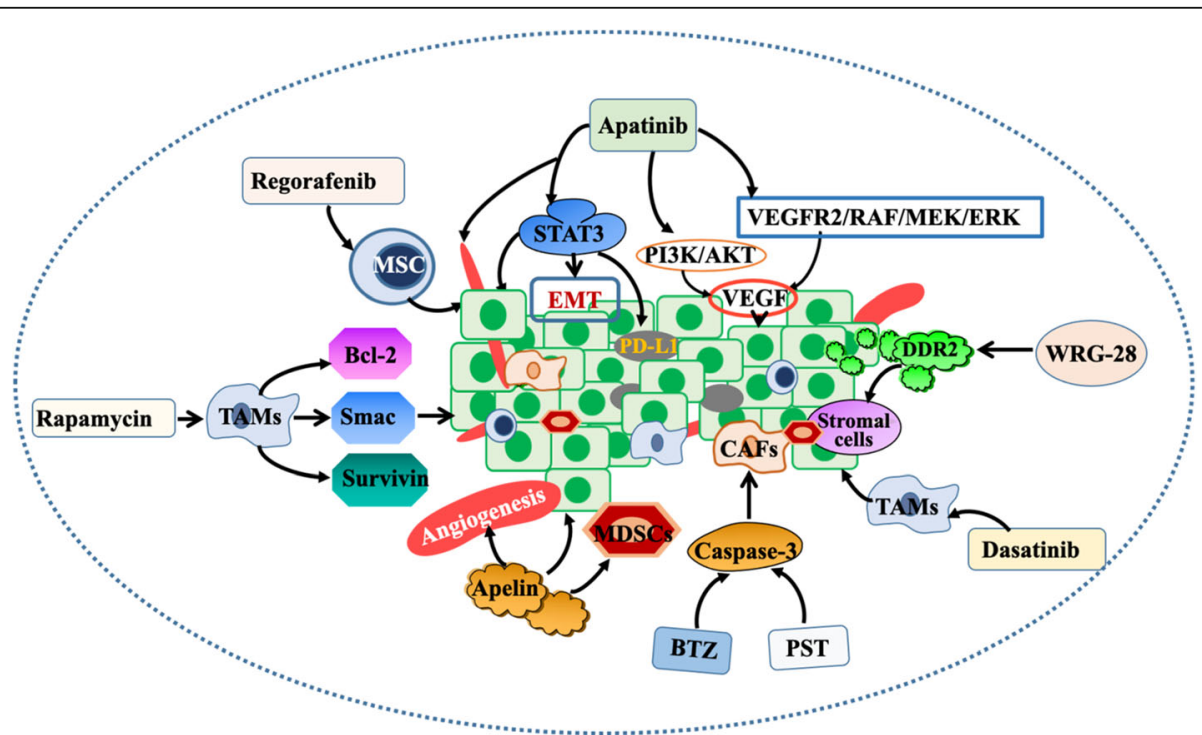

Fig. 3 Intervention of targeted therapy on the TME. Regorafenib inhibits the interaction between mesenchymal stem cells (MSCs) and cancer cells. Rapamycin-mediated autophagy can reduce the expression of Bcl-2 and survivin and increase the expression of Smac in TAMS. Apatinib can reduce cancer angiogenesis and inhibit the expression of PD-L1 through targeted STAT3 inhibition of the EMT and blockade of the PI3K/AKT and VEGFR2/RAF/MEK/ERK signalling pathways, thus affecting VEGF-mediated cell proliferation and invasion. WRG-28 inhibits cancer invasion and migration by targeting DDR2. Dasatinib reduced the M2 polarization of TAMS. Bortezomib (BTZ) and phenobarbital (PST) can reduce the survival rate of CAFs and inhibit the proliferation of cancer cells by inducing caspase-3-mediated apoptosis. The inhibition of apelin can inhibit angiogenesis and growth, and reduce the infiltration of suppressor cells derived from the polymorphonuclear myeloid system 
can inhibit the growth of colorectal cancers, prolong the survival time of mice and reduce cardiotoxicity [129].

Similarly, for cisplatin-resistant non-small-cell lung cancer, dasatinib inhibited the self-renewal ability of H460R and A549R cells and reduced the M2 polarization of TAMS [130]. Takigawa et al. suggested that regorafenib affects the interaction between MSCs and cancer cells by targeting the TME, thus inhibiting the proliferation and migration of colon cancers in mice [98]. In a randomized, placebo-controlled phase II clinical trial, tasquiimod, a new oral targeted therapy for the TME, increased progression-free survival (PFS) in prostate cancer patients with (MCRPC) metastatic castration resistance [131]. Targeted therapy is a part of precision therapy, but for some cancers, its curative effect is not obvious, and there are some limitations and side effects. Therefore, while exploring potential targets and targeted drugs, it may be more important to apply the existing research results to the clinical setting and investigate how to better cooperate with other treatment methods to enhance the therapeutic effect.

\section{Immunotherapy drugs for the TME}

Cancer immunotherapy is a type of immune function that stimulates or removes immunosuppression as a cancer treatment strategy to effectively inhibit cancer development. It produces immune memory, effectively restrains the resistance of malignant cancer to prevent the proliferation of cancer recurrence, restarts and maintains cancer-immune circulation, and restores the body's normal anticancer immune responses. The goal of cancer immunotherapy is to initiate a self-sustaining cancer immune cycle that can self-amplify and spread while minimizing the self-inflammation associated with treatment [132] (Fig. 4).

Immunotherapy has a unique mechanism of action on stromal cells. Clinically, cytotoxic $\mathrm{T}$ lymphocyte associated protein 4 (CTLA-4) and programmed cell death protein 1 (PD-1) are two checkpoints that can be successfully targeted [99]. Zhang et al. developed a new generation of anti-CTLA-4 antibodies. Preclinical studies have proven that they selectively consume regulatory $\mathrm{T}$ cells in the TME to enhance antibody-dependent cellmediated cytotoxicity/phagocytosis (ADCC/ADCP) and reduce immunotherapy-related adverse events (IRAEs) [100]. The preservation of CTLA-4 checkpoints may be more effective in removing Tregs from the TME, thus improving the efficacy [101].

On the other hand, anti-PD-L1/PD-1 antibodies can restore $\mathrm{T}$ cell immunity by interfering with the PD-L1/ PD-1 pathway, which leads to lasting remission in some cancer patients [102]. Tauriello et al. found the inhibition of liver metastasis of colon cancer by transforming growth factor $\beta$ in mice, thus releasing cytotoxic $T$ cells to respond to cancer cells to prevent metastasis, and thus, the use of TGF- $\beta$ inhibitors to achieve immunoosmosis is sufficient to increase the sensitivity to antiPD-1/PD-L1 checkpoint therapy [103]. It is not surprising that the combination of TGF- $\beta$ inhibitors and antiPD-L1 antibodies can reduce the TGF- $\beta$ signal in stromal cells, promote $\mathrm{T}$ cell infiltration to the cancer centre, and stimulate anti-cancer immunity and cancer

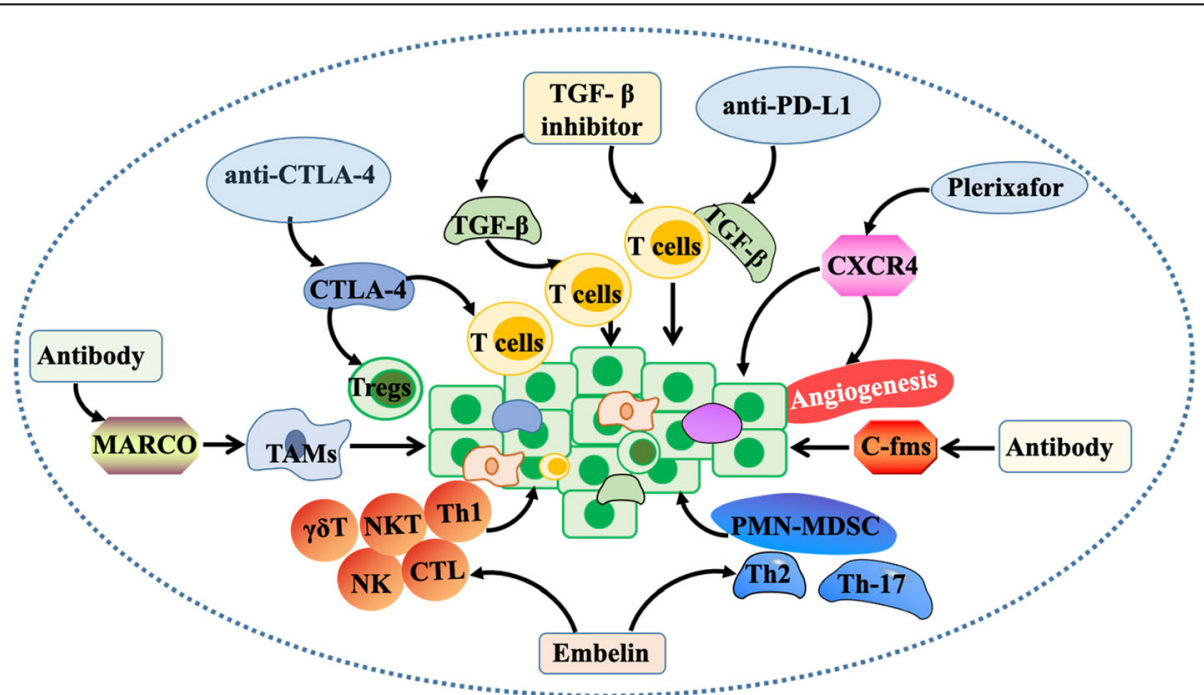

Fig. 4 Intervention of immunotherapy on the TME. Anti-CTLA-4 antibody consumes regulatory $T$ cells and removes Tregs. The use of transforming growth factor- $\beta$ (TGF- $\beta$ ) inhibitors and anti-PD-L1 antibodies can reduce the TGF- $\beta$ signal and promote the infiltration of T cells into the cancer centre. Plerixafor inhibits CXCR4 and reduces cancer spread and angiogenesis. Embelin can regulate the cancer-immune microenvironment by increasing the infiltration of Th1 cells, NK cells, CTLs, YST cells and NKT cells, reducing the infiltration of Th17, PMN-MDSCs, and IL-8- and IL-6-positive immune cells. Anti-c-FMS antibody affects the establishment of breast cancer cells in bone 
regression [133]. In the preclinical model of prostate cancer, the inhibition of CXCR4 by plerixafor can reduce invasiveness in vitro, which in turn reduces cancer spread and related angiogenesis [134].

In addition, Georgoudaki et al. found that in breast and colon cancer as well as melanoma models, immunotherapy with "macrophage receptor with collagen structure" (MARCO) can prevent cancer proliferation and migration and improve the immunogenicity of the TME. E-programming of macrophages in the TME with monoclonal antibodies is a feasible method for cancer immunotherapy [135]. Marsh et al. found that embelin can inhibit the growth of pancreatic cancer in KrasG12D mice by increasing the infiltration of Th1 cells, NK cells, CTLs, $\gamma \delta \mathrm{T}$ cells and NKT cells, and reducing the infiltration of Th17, PMN-MDSC, and IL-8- and IL-6positive immune cells, thus regulating the cancerimmune microenvironment [136]. Jeffery et al. proved for the first time that anti-c-FMS antibody affects the establishment of breast cancer cells in bone through a mouse model of breast cancer [137].

Immunotherapy is changing the treatment of solid cancers, and current clinical work is focused on developing immunotherapy combinations to transform nonresponders into responders, deepen their responses, and overcome their drug resistance. Therefore, the identification of immune markers can predict the response potential of immunotherapy and determine the best combination of immunotherapy for specific patients to carry out effective immunotherapy for cancer patients [138]. For example, human epidermal growth factor receptor $-2^{+}\left(\right.$HER $\left.-2^{+}\right)$breast cancer and TNBC are more likely to have interstitial infiltrating immune cells (TILs), than luminal breast cancer, and there is a linear relationship between the TILs content and clinical results. The possibility of expressing programmed death ligand-1 (PD-L1) in the TME is also higher than that in luminal breast cancer [139-141].

Progression-free survival and overall survival were longer in stage III NSCLC patients undergoing chemoradiotherapy when the density of CD8+ cancer-infiltrating lymphocytes in the pre-treated biopsy specimens was higher than that in patients with low CD8+ cancer infiltrating lymphocyte density [142]. This is through the immune mechanism to improve disease control, and thus, the baseline cancer-infiltrating lymphocyte status can be used as a predictive biomarker of checkpoint inhibitory immunotherapy and as a prognostic biomarker. There may also be a variety of immunosuppressive mechanisms in the TME, including CTLA-4, PD-L2 and interleukins [143]. Strategies that combine multiple approaches to detect the immune status of the TME may be more effective in treating immune checkpoint inhibitors [144].
As a new treatment, immunotherapy is not aimed at tissues and cancer cells but at the body's own immune system to change the immune state of the TME and prevent and treat cancer progression. However, although the therapeutic effect is good, the proportion of the effective population is low. Therefore, the establishment of predictive biomarkers of checkpoint immunotherapy is very important to maximize the effectiveness of treatment. For patients for whom immunotherapy is ineffective at the current checkpoint, unnecessary toxicity can be avoided in time, and alternative treatment strategies can be adopted. Although immunotherapy research is in a bottleneck at present, it has broad application prospects in the clinical setting.

\section{Nanoparticle system intervention for the TME}

The use of nanocarriers not only increases the bioavailability and solubility of hydrophobic drugs but also improves the pharmacokinetic properties of drugs, avoids the degradation of drugs in vivo circulation, and delivers one or more drugs to the lesion site to achieve the controlled release of drugs. Nanotechnology helps to improve the targeting efficiency, has received increasing attention, and has been used in a variety of treatments, such as chemotherapy, radiotherapy and immunotherapy [145] (Fig. 5).

In recent years, stimulus-sensitive or intelligent nanocarriers have attracted much attention because of their advantages in controlling the release of drugs. By replying to external stimuli (e.g., ultrasound and magnetism) or internal stimuli (e.g., temperature, $\mathrm{pH}$, and $\mathrm{H}_{2} \mathrm{O}_{2}$ ), medicine can be controllably released from smart nanocarriers at the therapeutic target in a desired manner [146-148].

Nanocarriers can improve the solubility of drugs, increase the stability of drugs, reduce toxicity and side effects, and specifically deliver medicinal molecules to cancers by heightened targeting effects or retention (EPR) effects and permeability [149, 150]. Moreover, nanocarriers can encapsulate various anticancer drugs with different treatment mechanisms and deliver them at the same time; therefore, they are very beneficial to the combined therapy of cancers [104, 105]. Zhang et al. demonstrated through in vivo experiments that targeted nanoparticles can remove pro-cancer cells and stimulate anti-cancer effector cells by loading immunomodulators (such as lipid nanoparticles coated with cancer-targeting peptides IRGD and PI3K inhibitors) [106]. This not only helps to reduce the toxicity and side effects of antineoplastic medicine, but also helps to exert the congenerous effect of different antineoplastic medicines [151].

In addition to the above effects, the material of the nanoparticles themselves also has a direct impact on the TME. Jiang et al. found that functionalized micelles 


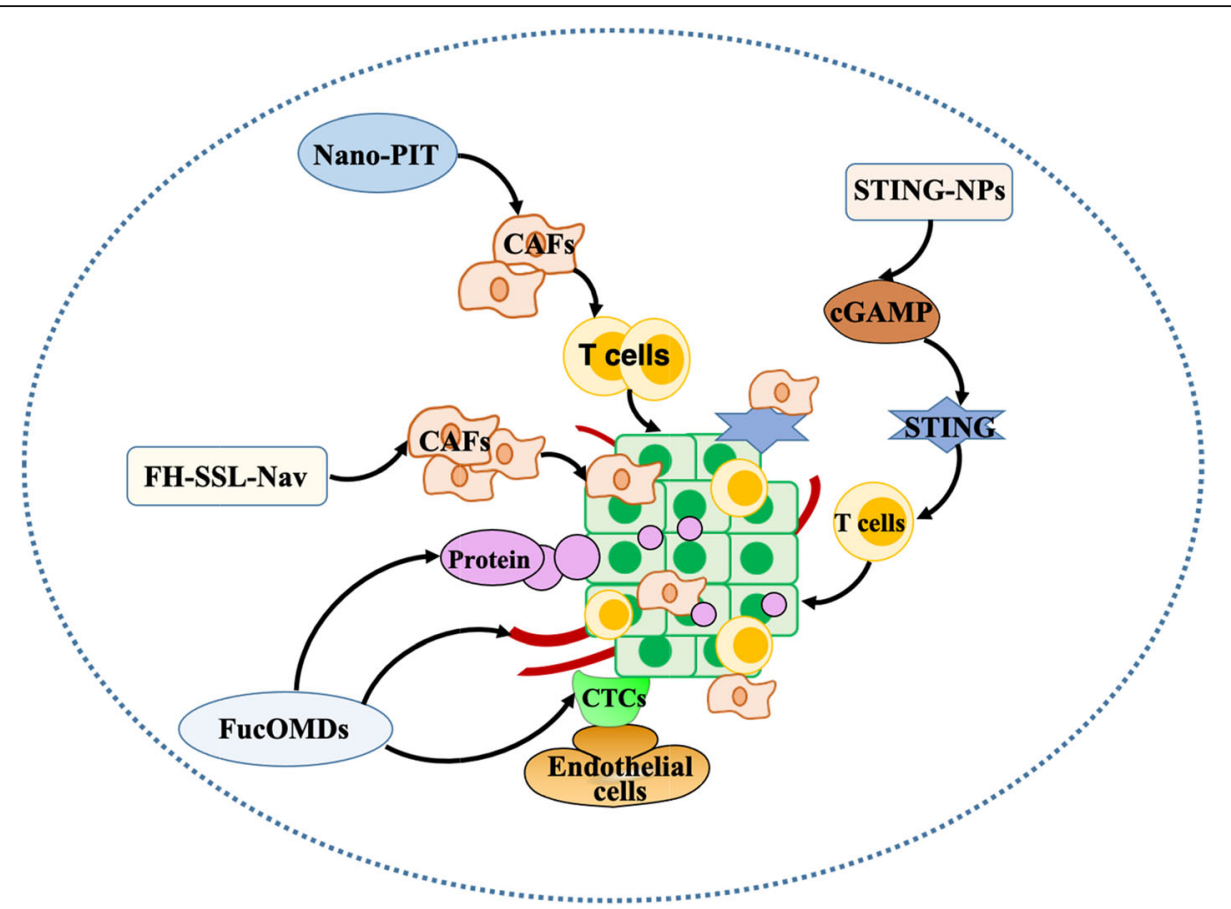

Fig. 5 Intervention of the nanoparticle-based drug delivery system in the TME. Functionalized micellar endothelial cells (FucOMDs) adhere to cancer cells and reverse the abnormal expression of several key marker proteins in the pre-metastatic niche. A new type of cancer matrixtargeted nanocarrier (FH-SSL-Nav) can remove CAFs. Photoimmunotherapy (nano-PIT) selectively kills CAFs and increases the invasiveness of T cells. Interferon gene-activated nanoparticle stimulator (STINNP) enhances the cytoplasmic delivery of cyclic guanosine monophosphateadenosine monophosphate (CGAMP) through an in vivo escape mechanism, activating STING and triggering T cells

(FucOMDs) target and have good blood circulation, which can inhibit the adhesion of activated endothelial cells to CTCs in triple-negative breast cancer mice and reverse the abnormal expression of several key marker proteins in the pre-metastatic niche [107]. Chen et al. discovered that a new type of cancer matrix-targeted nanocarrier (FH-SSL-Nav) can specifically remove CAFs from the liver cancer model to promote the penetration of nanodrugs into the cancer and cut off the support of the matrix to cancer cells [108]. In addition, Zhen and others also put forward their own point of view, indicating that the selective killing of CAFs and nanoparticlebased photoimmunotherapy (nano-PIT) can increase the invasiveness of $\mathrm{T}$ cells, thus effectively inhibiting cancer, which has also been proven by in vivo experiments [109].

At present, research on nanoparticle systems is mainly focused on accurate drug delivery, precise controlled release, and the efficacy of the material itself. As an ideal adjuvant therapy, there is no denying its advantages and bright prospects in clinical application. However, everything has two sides, and we do not have a deep understanding of it nor are we very clear about its side effects. Therefore,we should evaluate it more comprehensively and examine it before it is used in the clinical setting.

\section{Natural products from traditional Chinese medicine for the TME}

Traditional Chinese medicine (TCM) has a long history and unique advantages. Based on the needs of the comprehensive treatment of clinical cancers, various natural products from TCM have been investigated in the therapy of cancers (Fig. 6).

Curcumin (diferuloylmethane) is an active ingredient in plant turmeric spices [152]. It suppresses tumour progression by affecting many aspects of the microenvironment. Based on in vivo and in vitro studies of ovarian cancer, curcumin interferes with the TME and affects tumour progression by inhibiting transcription factor nuclear factor-NB (NF-NB), signal transduction, activation of transcriptional activator 3 and expression of angiogenic cytokines [110]. For pancreatic cancer, preclinical studies have found that a new curcumin synthesis derivative (CDF) can inhibit VEGF, IL-6 and tumour stem cells, thus affecting the TME of pancreatic cancer [111]. In addition, a randomized phase 1 placebocontrolled trial of the APG-157 botanical drug made from curcumin was conducted. A total of 13 normal subjects and 12 oral cancer subjects participated in the study, of which 12 were treated with placebo and 13 were treated with the active drug APG-157. It was found that the infiltrating expression of immune cells $\left(\mathrm{CD} 4^{+}\right.$ 


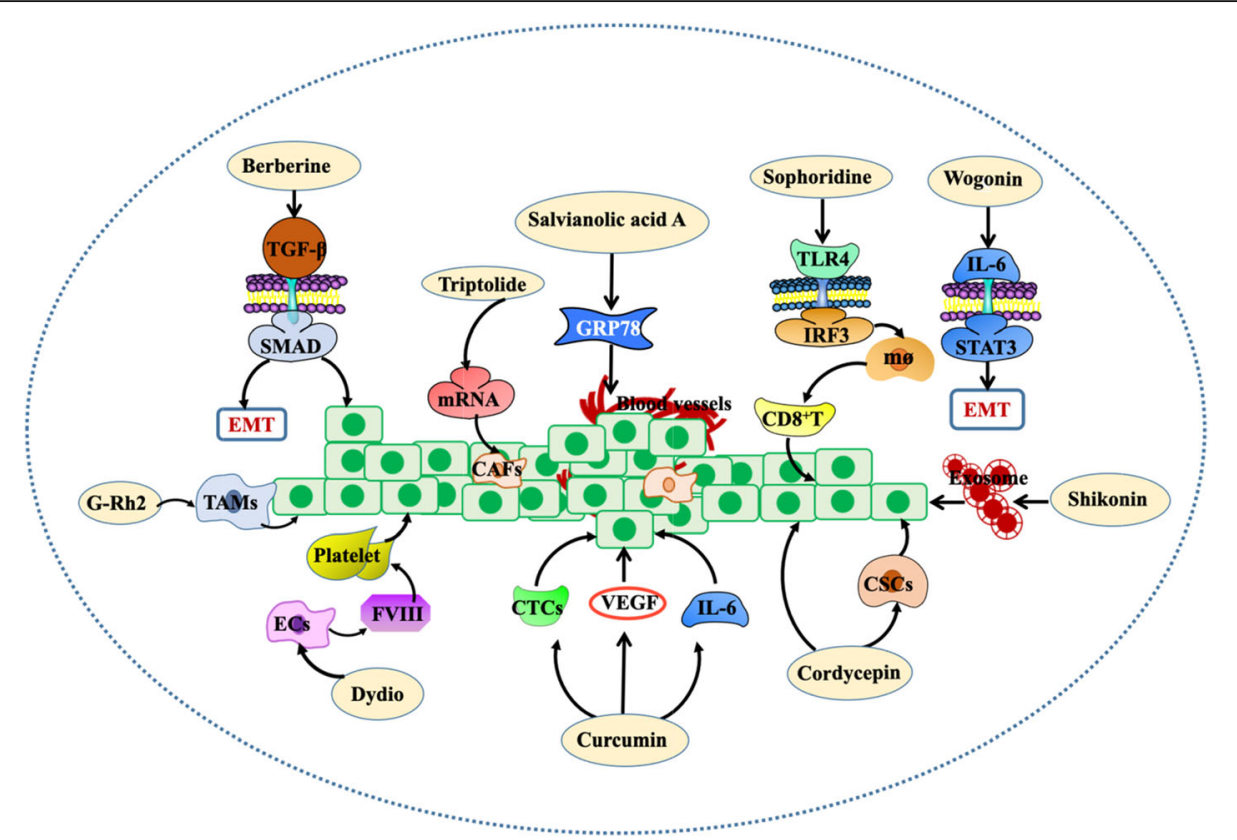

Fig. 6 Intervention of natural products from traditional Chinese medicine on the TME. Curcumin inhibits VEGF, IL-6 and cancer stem cells in vivo and in vitro. Ginsenoside Rh2 (G-Rh2) can regulate the phenotype of TAMs to improve the TME. Dihydrodiosgenin (DYDIO) can inhibit platelet activation and reduce endothelial cell-derived factor VIII (FVIII). Cordycepin can target CSCS and upregulate the apoptosis of cancer cells. Shikonin reduces cancer-derived exosomes to inhibit the spread of breast cancer cell lines. Wogonin inhibits the transformation of EMT into the epithelial stroma by interfering with the IL-6/STAT3 signalling pathway. Sophoridine can inhibit macrophage-mediated immunosuppression through the TLR4/IRF3 pathway and then upregulate the killing effect of $\mathrm{CD}^{+} \mathrm{T}$ cells on gastric cancer. Salvianolic acid A can block the secretion of glucoseregulated protein 78 (GRP78) and inhibit angiogenesis. Triptolide (TP) inhibits the proliferation of cancer cells. Berberine can mediate the transforming growth factor- $\beta$ signalling pathway, thus inhibiting EMT and promoting apoptosis

and $\mathrm{CD}^{+}$cells) and the expression of PD-1 and PD-L1 were significantly increased in patients receiving APG157, implying that APG-157 therapy has the potential to attract immune cells into the TME and provides a strong theoretical basis for using immune checkpoints to block the interaction between $\mathrm{T}$ cells and cancer cells (PD-1/ PD-L1 axis) [112]. In a randomized, double-blind, placebo-controlled trial, 97 patients were randomly divided into a curcumin group $(n=49)$ and a placebo group $(n=48)$. Oral curcumin for 6 months had no significant effect on the overall withdrawal time of prostate cancer patients with intermittent androgen deprivation, and curcumin intake inhibited the increase in prostatespecific antigen (PSA) during curcumin administration. It has been suggested that curcumin has a potential beneficial effect on patients with prostate cancer [113]. Curcumin not only intervenes the TME but also improves the safety and tolerance of patients to a certain extent, suggesting that while traditional Chinese medicine plays an anti-cancer role, it is also helpful for the self-protection of patients.

By interfering with the target or signalling pathway in the microenvironment, TCM can inhibit the microenvironment aiding cancer through immunosuppression, the EMT and cancer stem cells. Through in vitro experiments, it was found that sophoridine can inhibit macrophage-mediated immunosuppression through the TLR4/IRF3 pathway and then up-regulate the killing effect of $\mathrm{CD}^{+} \mathrm{T}$ cells on gastric cancer, thus reshaping the immune microenvironment of gastric cancer, which provides a preclinical basis for the clinical application of sophoridine [114]. Research by $\mathrm{Li}$ et al. indicated that ginsenoside Rh2 (G-Rh2) can improve the TME by regulating the phenotype of TAMs in lung cancer tissues [115]. Huang et al. demonstrated that berberine can mediate Smad-independent and Smad-dependent TGF- $\beta$ signalling pathways, thereby inhibiting EMT and promoting apoptosis [116]. Zhao et al. found that wogonin inhibits EMT in the inflammatory microenvironment by interfering with the IL-6/STAT3 signalling pathway in mice with lung cancer [153]. Li et al. found that for the mouse model of metastasis of human colon cancer, Bigelovin inhibits the EMT by interfering with the expression of $\mathrm{N}$-and $\mathrm{E}$-cadherin, inhibits colony formation through the STAT3 pathway, and reduces cell invasion through the cofilin pathway [117]. Jin et al. demonstrated that cordycepin regulates the TME and inhibits cancer growth by targeting CSCs, upregulating cancer cell apoptosis and eliciting cell cycle arrest [118]. 
The TCM can reduce or block the communication between cells in the TME, thus destroying the microenvironment and inhibiting cancer metastasis. The TCM can affect the communication between cells in the TME, thus inhibiting cancer proliferation. Wei et al. provided evidence that shikonin checks the diffusion of a breast cancer cell line (MCF-7) by reducing the exosome of cancer origin [119]. Through in vivo experiments, Liu et al. showed that the triptolide exosome delivery system (TP-Exos) can reduce the apoptosis and cytotoxicity of TP on SKOV3 cells and enhance the inhibitory effect of TP on cell proliferation [154].

Some studies have also shown the effect of natural products from TCM on improving the TME by promoting vascular normalization. Zhong et al. found that 6gingerol (6G) reduces cancer growth and metastasis by promoting cancer vascular normalization, reducing microvascular structure entropy (MSE), improving the TME and reducing cancer metastasis in a patientderived cancer xenotransplantation (PDTX) model [155]. Yang et al. demonstrated that salvianolic acid A can block the secretion of glucose-regulated protein 78 (GRP78) to inhibit cancer-related angiogenesis [156]. Zhuang et al. demonstrated that dihydrodiosgenin (DYDIO) can inhibit platelet activation and reduce endothelial cell-derived factor VIII (FVIII) to inhibit HCC metastasis [157].

There are many types of TCMs that can act on different signalling pathways in the TME, inhibit cancer recurrence and metastasis, have high safety, and can be treated according to the patient's physique, syndrome differentiation and precise treatment. However, there are few modern pharmacological studies of TCM, and most of them are preclinical studies. Therefore, more in-depth exploration is needed for broad clinical practice.

\section{Combination therapy for the TME}

To better intervene in the TME, combination therapy may be a good strategy, such as the combination of two different chemotherapy drugs or a combination of chemotherapy drugs and natural products from TCM (Fig. 7).

\section{Combination of chemotherapy}

Chemotherapeutic drugs used in combination with other types of drugs or different chemotherapeutic drugs have a good effect on improving the TME. For example, Guo et al. found that rapamycin (RapA) is a mTOR inhibitor that can provide significant efficacy in the treatment of melanoma in xenograft models through antiangiogenic

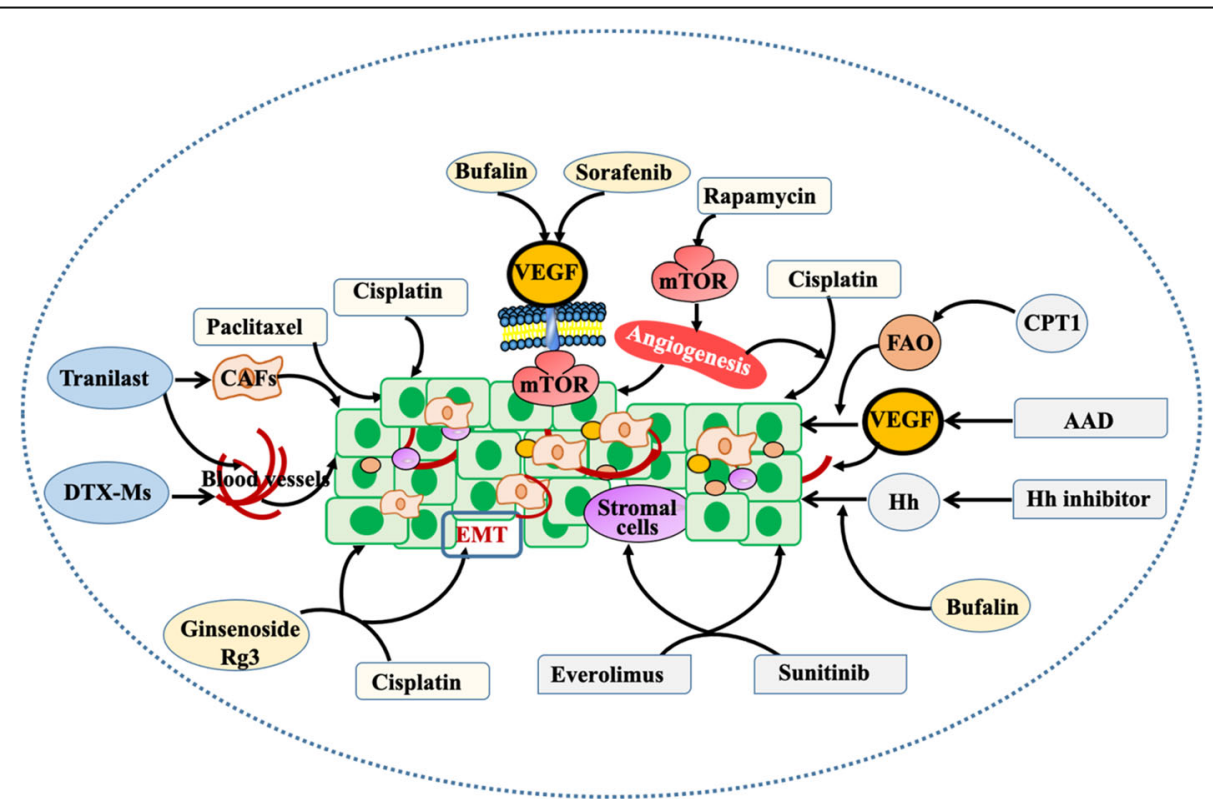

Fig. 7 Intervention of combined drugs on the TME. Rapamycin (RapA) is a mTOR inhibitor that inhibits tumour proliferation through antiangiogenesis and can be enhanced in combination with cisplatin. Cisplatin combined with paclitaxel inhibits tumour invasion. The combination of everolimus and sunitinib can affect stromal cells and cancer cells in the TME. Antiangiogenic drugs (AADs) combined with carnitine palmitoyltransferase 1A (CPT1) inhibitors significantly inhibited fatty acid oxidation (FAO) -induced cell proliferation and angiogenesis. Ginsenoside Rg3 combined with cisplatin can inhibit epithelial-mesenchymal transition (EMT) of tumour cells. Hedgehog (HH) signalling pathway inhibitors combined with bufalin can inhibit tumour proliferation. Tranilast can dow-regulate CAF activity, promote vascular normalization, and help docetaxel micelles (DTX-ms) reach tumour tissue through veins and kill tumour cells. Sorafenib combined with bufalin affects the tumour vascular microenvironment through targeting the mTORNEGF signalling pathway 
activity and can be co-cultured with cisplatin because RAPA makes A375 melanoma cells sensitive to cisplatin through microenvironmental regulation [122]. Chemotherapy resistance is widely considered to be one of the main factors that limit the therapeutic effect of cancer patients and affect the clinical outcome. In the first phase clinical trial, Heeren et al. proved that cisplatin combined with paclitaxel has a stronger regulatory effect on cancer invasion than cisplatin alone [158].

\section{Combination of targeted therapy}

The combination of targeted drugs can interfere with the TME and inhibit cancer growth and invasion from many aspects and multiple targets. The results of Kitano et al. suggested that the combination of everolimus and sunitinib effectively inhibited the TME composed of mesenchymal and cancer cells in renal carcinoma models [159].

Targeting cancer angiogenesis is a good intervention method. Interestingly, in the fatty liver model of liver metastasis of liver cancer and colon cancer, Iwamoto et al. discovered that cancer hypoxia induced by antiangiogenic drugs (AADs) can initiate fatty acid oxidative metabolism reprogramming, increase free fatty acid (FFA) uptake, and thus stimulate cancer cell proliferation. Reducing carnitine palmitoyltransferase 1A (CPT1) can significantly inhibit cell proliferation induced by FFA. Therefore, the deletion of CPT1 can enhance the therapeutic effect of AAD and its anti-cancer effect [160].

In addition, the combination of poly (adenosine diphosphate-ribose) polymerase (PARP) inhibitor and mitogen-activated protein kinase (MEK) inhibitor produces a synergistic cytotoxic effect in a variety of RAS mutant tumor models in vitro and in vivo. It induces BIM-mediated apoptosis by activating caspase-3, inhibits the expression of CD31 in endothelial cells, and inhibits the production of mutant RAS-induced VEGF through the RAS/MAPK pathway, thus affecting the vascular microenvironment [120]. PARP inhibitors were the first cancer drug to synthesize lethal targeted therapy and the first clinically approved drug to take advantage of synthetic lethal advantages [121]. Synthetic lethality (SL) is a concept put forward by geneticists nearly a century ago to describe a situation in which either defect in two genes has little effect on a cell or organism, but a combination of defects in the two genes may lead to death [161]. For example, a prospective phase III trial (POLO trial, ongoing pancreatic cancer Oraparib, NCT02184195) was recently conducted to evaluate the efficacy of olapril in patients with BRCA mutation and metastatic PDAC [162]. Furthermore, preclinical trials showed that PARPI could upregulate PD-L1 expression directly or indirectly by promoting the activation of the IFN pathway $[123,124]$.

\section{Combined with TCM therapy}

In an open-label randomized controlled trial, Lynne et al. found that curcumin combined with the FOLFOX regimen in the treatment of stage IIa metastatic colorectal cancer can improve the safety and tolerance of cancer patients and improve the therapeutic effect [163]. In addition, Sheng et al. also proposed their own point of view, indicating that the combination of hedgehog (Hedgehog, HH) signal pathway inhibitors and bufalin can significantly reduce the malignant biological behaviour of liver cancer [164]. Wang et al. found that sorafenib combined with bufalin affected the cancer vascular microenvironment by targeting the mTOR/VEGF signalling pathway in mice with liver cancer, thus exerting a synergistic anti-liver cancer effect [165]. In solid cancers, hypoxia changes the microenvironment and is related to proliferation, metastasis and drug sensitivity. Wang et al. showed that ginsenoside Rg3 combined with cisplatin can significantly reverse the dryness and EMT of nonsmall-cell lung cancer (NSCLC) cells induced by hypoxia in vivo and in vitro [166].

\section{Others}

Additionally, the combination of other cancer therapies also has a good effect on the TME. Pang et al. discovered that pre-administration of tranilast can downregulate the activity of CAFs, cut off the relationship between cancer cells and CAFs, and facilitate vascular normalization. Docetaxel micelles (DTX-ms) then pass through nearby veins to reach the cancer tissue. Due to the improved retention (EPR) effect and permeability, the micelles were passively trapped in the cancer and further spread to the interior to kill cancer cells [167].

By exerting the synergistic therapeutic effect of drugs, combined drugs can interfere with the TME from many aspects (such as immunity, angiogenesis, EMT or hypoxia), destroy the soil of cancer growth and metastasis to improve treatment efficacy, inhibit drug resistance and prevent cancer metastasis. This is indispensable in the mode of the comprehensive treatment of cancers.

\section{Conclusions and perspectives}

TME is the soil of cancer growth and metastasis. The primary TME promotes cancer growth and development, and the pre-metastatic microenvironment provides the end point for disseminated cancer cells and prepares for cancer metastasis, while the metastatic microenvironment awakens dormant disseminated cancer cells and finally forms metastatic foci. Therefore, when taking the TME as the intervention target, it is best to detect the specific state of the current TME, such 
as detecting immune markers, and introduce therapeutic drugs at the right time. Only in this way can we better inhibit or even block the invasion and metastasis of the cancer and provide the basis for the further elimination of the cancer. Of course, the detection of the TME is still a problem that may be solved by measuring cells, body fluids and cytokines in serum.

Currently, the intervention methods for the TME include chemotherapy, targeted therapy, immunotherapy, TCM therapy and so on. Compared with single therapy, combined therapy can interfere with multiple targets in the TME at the same time to achieve the effect of cooperative therapy, quickly destroy the interaction between the TME and cancer cells, and prevent and treat cancer metastasis. However, these have yet to be verified in clinical trials. Moreover, it is not clear how to use drugs in combination, such as the conditions of combined use, the antagonism between drugs, the order before and after combined use, and so on. Although these studies still have a variety of limitations, with the arrival of the era of the comprehensive treatment of the cancer model, combined therapy intervention of the TME has a good development prospects.

\section{Abbreviations}

TME: Tumor microenvironment; VECs: Vascular endothelial cells; VEGF: Vascular endothelial growth factor; ECM: Extracellular matrix; CAFs: Cancer-associated fibroblasts; TAMs: Tumor-associated macrophages; BMDCs: Bone marrow-derived dendritic cells; MDSCs: Myeloid-derived suppressor cells; FGF: Fibroblast growth factor; EGF: Epidermal growth factor; PDGF: Platelet-derived growth factor; TGF: Transforming growth factor; HSC: Hepatic stellate cells; ANG-1: Angiopoietin-1; EVs: Extracellular vesicles; ITGBL1: Integrin 31 ; CRC: Colorectal cancer; HIC-5: Hydrogen peroxideinduced clone 5; ESCC: Esophageal squamous cell carcinoma; EMT: Epithelialmesenchymal transition; MSCs: Mesenchymal stem cell; GALNT14: Nacetylgalactosamine transferase 14; PMN: Pre-metastatic niche; eATP: extracellular ATP; DTCs: Disseminated tumor cells; TF: Tissue factor; LOX: Lysyl oxidase; HPC: Hematopoietic progenitor cell; OXP: Oxaliplatin; PDAC: Pancreatic ductal adenocarcinoma; XIST: X-inactivated specific transcript; $m C R P C$ : metastatic castration resistance to prostate cancer; PFS: Progression-free survival; BTZ: Bortezomib; PST: Penobarbital; PSS: Propylene glycol alginate sodium sulfate; DOX: Doxorubicin; HCC: Hepatocellular carcinoma; RPS15A: Ribosomal protein s15a; CTLA4: Cytotoxic T lymphocyte associated protein 4; PD-1: Programmed cell death protein 1; CTCS: Circulating tumor cells; TCM: Traditional Chinese medicine; DYDIO: Dihydrodiosgenin; APS: Astragalus polysaccharide; ER: Endoplasmic reticulum; MSE: Microvascular structure entropy; RAPA: Rapamycin; AAD: Antiangiogenic drug; CPT1: Carnitine palmitoyltransferase 1A; NSCLC: Non-small cell lung cancer

\section{Acknowledgements}

Not applicable.

\section{Authors' contributions}

$L H Z, J Z, J Q$ and LQ conceived the structure of manuscript and revised the manuscript. $\mathrm{LHZ}$ and $\mathrm{ZLH}$ made the figures $J \mathrm{Q}$ and $\mathrm{LQ}$ reviewed the manuscript. All authors read and approved the final manuscript.

\section{Funding}

This work was supported by National Science Foundation of China (82030118, 81830120, 81520108031 to Q.L.; 82074225 to Q.J.; 81973651 to L.Z.), 3 year plan of action for innovation of traditional Chinese medicine in Shanghai (ZY2020-CCCX-2003-03 to Q.L.), Key project of Shanghai Municipal Science and Technology Commission (16401970500 to Q.L.).
Availability of data and materials

Not applicable.

\section{Declarations}

Ethics approval and consent to participate

Not applicable.

\section{Consent for publication}

Not applicable.

\section{Competing interests}

The authors declare that they have no competing interests.

\section{Author details}

'Department of Medical Oncology and Cancer Institute, Shuguang Hospital, Shanghai University of Traditional Chinese Medicine, Shanghai 201203, China.

${ }^{2}$ Academy of Integrative Medicine, Shanghai University of Traditional Chinese Medicine, Shanghai 201203, China.

Received: 13 November 2020 Accepted: 24 February 2021

Published online: 15 March 2021

\section{References}

1. Siegel RL, Miller KD, Jemal A. Cancer statistics, 2020. CA Cancer J Clin. 2020; 70(1):7-30.

2. Kato $T$, Hwang $R$, Liou $P$, et al. Ex vivo resection and autotransplantation for conventionally Unresectable tumors - an 11-year single center experience. Ann Surg. 2020;272(5):766-72.

3. Von Hoff DD, Ervin T, Arena FP, et al. Increased survival in pancreatic cancer with nab-paclitaxel plus gemcitabine. N Engl J Med. 2013;369(18):1691-703.

4. Paget S. The distribution of secondary growths in cancer of the breast. 1889. Cancer Metastasis Rev. 1989;8(2):98-101.

5. Liu Y, Cao X. Characteristics and significance of the pre-metastatic niche. Cancer Cell. 2016;30(5):668-81.

6. Ioannides CG, Whiteside TL. T cell recognition of human tumors: implications for molecular immunotherapy of cancer. Clin Immunol Immunopathol. 1993;66(2):91-106.

7. Albini A, Magnani E, Noonan DM. The tumor microenvironment: biology of a complex cellular and tissue society. Q J Nucl Med Mol Imaging. 2010; 54(3):244-8.

8. Weston WW, Ganey T, Temple HT. The relationship between Exosomes and Cancer: implications for diagnostics and therapeutics. BioDrugs. 2019;33(2): 137-58.

9. Muller PA, Vousden $\mathrm{KH}$. Mutant p53 in cancer: new functions and therapeutic opportunities. Cancer Cell. 2014;25(3):304-17.

10. Olive KP, Tuveson DA, Ruhe ZC, et al. Mutant p53 gain of function in two mouse models of Li-Fraumeni syndrome. Cell. 2004;119(6):847-60.

11. Hientz K, Mohr A, Bhakta-Guha D, Efferth T. The role of p53 in cancer drug resistance and targeted chemotherapy. Oncotarget. 2017;8(5):8921-46.

12. Tahmasebi Birgani M, Carloni V. Tumor microenvironment, a paradigm in hepatocellular carcinoma progression and therapy. Int J Mol Sci. 2017;18(2): 405.

13. Schaafsma E, Yuan Y, Zhao Y, Cheng C. Computational STAT3 activity inference reveals its roles in the pancreatic tumor microenvironment. Sci Rep. 2019;9(1):18257.

14. Panni RZ, Sanford DE, Belt BA, et al. Tumor-induced STAT3 activation in monocytic myeloid-derived suppressor cells enhances stemness and mesenchymal properties in human pancreatic cancer. Cancer Immunol Immunother. 2014;63(5):513-28.

15. Takaishi K, Komohara Y, Tashiro H, et al. Involvement of M2-polarized macrophages in the ascites from advanced epithelial ovarian carcinoma in tumor progression via Stat3 activation. Cancer Sci. 2010;101(10):2128-36.

16. Yue C, Shen S, Deng J, et al. STAT3 in CD8+ T cells inhibits their tumor accumulation by Downregulating CXCR3/CXCL10 Axis. Cancer Immunol Res. 2015;3(8):864-70.

17. D'Amico S, Shi J, Martin BL, Crawford HC, Petrenko O, Reich NC. STAT3 is a master regulator of epithelial identity and KRAS-driven tumorigenesis. Genes Dev. 2018;32(17-18):1175-87. 
18. Yang $X$, Lin $Y$, Shi $Y$, et al. FAP promotes immunosuppression by Cancerassociated fibroblasts in the tumor microenvironment via STAT3-CCL2 signaling. Cancer Res. 2016;76(14):4124-35.

19. Butler JM, Kobayashi H, Rafii S. Instructive role of the vascular niche in promoting tumour growth and tissue repair by angiocrine factors. Nat Rev Cancer. 2010;10(2):138-46.

20. Junttila MR, de Sauvage FJ. Influence of tumour micro-environment heterogeneity on therapeutic response. Nature. 2013;501(7467):346-54.

21. Maishi N, Hida K. Tumor endothelial cells accelerate tumor metastasis. Cancer Sci. 2017;108(10):1921-6.

22. Yuan Y, Jiang YC, Sun CK, Chen QM. Role of the tumor microenvironment in tumor progression and the clinical applications (review). Oncol Rep. 2016; 35(5):2499-515.

23. Bekes EM, Schweighofer B, Kupriyanova TA, et al. Tumor-recruited neutrophils and neutrophil TIMP-free MMP-9 regulate coordinately the levels of tumor angiogenesis and efficiency of malignant cell intravasation. Am J Pathol. 2011:179(3):1455-70.

24. Wada Y, Yoshida K, Tsutani Y, et al. Neutrophil elastase induces cell proliferation and migration by the release of TGF-alpha, PDGF and VEGF in esophageal cell lines. Oncol Rep. 2007;17(1):161-7.

25. Yin $Y$, Yao S, Hu Y, et al. The immune-microenvironment confers Chemoresistance of colorectal Cancer through macrophage-derived IL6. Clin Cancer Res. 2017;23(23):7375-87.

26. Quail DF, Joyce JA. Microenvironmental regulation of tumor progression and metastasis. Nat Med. 2013;19(11):1423-37.

27. Chen Z, Zhou L, Liu L, et al. Single-cell RNA sequencing highlights the role of inflammatory cancer-associated fibroblasts in bladder urothelial carcinoma. Nat Commun. 2020;11(1):5077.

28. Gehmert S, Lehoczky G, Loibl M, Jung F, Prantl L, Gehmert S. Interaction between extracellular cancer matrix and stromal breast cells. Clin Hemorheol Microcirc. 2020;74(1):45-52.

29. Urooj T, Wasim B, Mushtaq S, Shah SNN, Shah M. Cancer cell-derived secretory factors in breast Cancer-associated lung metastasis: their mechanism and future prospects. Curr Cancer Drug Targets. 2020;20(3):16886.

30. Nagarsheth N, Wicha MS, Zou W. Chemokines in the cancer microenvironment and their relevance in cancer immunotherapy. Nat Rev Immunol. 2017:17(9):559-72.

31. Lin N, Meng L, Lin J, et al. Activated hepatic stellate cells promote angiogenesis in hepatocellular carcinoma by secreting angiopoietin-1. J Cell Biochem. 2020;121(2):1441-51.

32. Becker A, Thakur BK, Weiss JM, Kim HS, Peinado H, Lyden D. Extracellular vesicles in Cancer: cell-to-cell mediators of metastasis. Cancer Cell. 2016; 30(6):836-48.

33. De Palma M, Biziato D, Petrova TV. Microenvironmental regulation of tumour angiogenesis. Nat Rev Cancer. 2017;17(8):457-74.

34. Keklikoglou I, Cianciaruso C, Güç E, et al. Chemotherapy elicits prometastatic extracellular vesicles in breast cancer models. Nat Cell Biol. 2019; 21(2):190-202.

35. Cianciaruso C, Beltraminelli T, Duval F, et al. Molecular Profiling and Functional Analysis of Macrophage-Derived Tumor Extracellular Vesicles. Cell Rep. 2019;27(10):3062-3080.e11.

36. Ji Q, Zhou L, Sui H, et al. Primary tumors release ITGBL1-rich extracellular vesicles to promote distal metastatic tumor growth through fibroblast-niche formation. Nat Commun. 2020:11(1):1211.

37. Fletcher M, Ramirez ME, Sierra RA, et al. L-arginine depletion blunts antitumor T-cell responses by inducing myeloid-derived suppressor cells. Cancer Res. 2015;75(2):275-83.

38. Meng W, Hao Y, He C, Li L, Zhu G. Exosome-orchestrated hypoxic tumor microenvironment. Mol Cancer. 2019;18(1):57.

39. Zhang X, Sai B, Wang F, et al. Hypoxic BMSC-derived exosomal miRNAs promote metastasis of lung cancer cells via STAT3-induced EMT. Mol Cancer. 2019;18(1):40.

40. Martin JD, Fukumura D, Duda DG, Boucher $Y$, Jain RK. Reengineering the tumor microenvironment to alleviate hypoxia and overcome Cancer heterogeneity. Cold Spring Harb Perspect Med. 2016;6(12):a027094.

41. Jing $X$, Yang $F$, Shao $C$, et al. Role of hypoxia in cancer therapy by regulating the tumor microenvironment. Mol Cancer. 2019;18(1):157.

42. Herrera M, Galindo-Pumariño C, García-Barberán V, Peña C. A snapshot of the tumor microenvironment in colorectal Cancer: the liquid biopsy. Int J Mol Sci. 2019;20(23):6016
43. Liu Y, Gu Y, Cao X. The exosomes in tumor immunity. Oncoimmunology. 2015:4(9):e1027472

44. Wortzel I, Dror S, Kenific CM, Lyden D. Exosome-mediated metastasis: communication from a distance. Dev Cell. 2019:49(3):347-60.

45. Shao Y, Chen T, Zheng X, et al. Colorectal cancer-derived small extracellular vesicles establish an inflammatory premetastatic niche in liver metastasis. Carcinogenesis. 2018;39(11):1368-79.

46. Guo Y, Ji X, Liu J, et al. Effects of exosomes on pre-metastatic niche formation in tumors. Mol Cancer. 2019;18(1):39.

47. Song $H$, Wang $T$, Tian $L$, et al. Macrophages on the peritoneum are involved in gastric Cancer peritoneal metastasis. J Cancer. 2019;10(22):5377-87.

48. Du X, Xu Q, Pan D, et al. HIC-5 in cancer-associated fibroblasts contributes to esophageal squamous cell carcinoma progression. Cell Death Dis. 2019; 10(12):873.

49. Pearson GW. Control of invasion by epithelial-to-Mesenchymal transition programs during metastasis. J Clin Med. 2019;8(5):646.

50. Micalizzi DS, Maheswaran S, Haber DA. A conduit to metastasis: circulating tumor cell biology. Genes Dev. 2017;31(18):1827-40.

51. Massagué J, Obenauf AC. Metastatic colonization by circulating tumour cells. Nature. 2016;529(7586):298-306.

52. Lamouille S, Xu J, Derynck R. Molecular mechanisms of epithelialmesenchymal transition. Nat Rev Mol Cell Biol. 2014;15(3):178-96.

53. Plaks $V$, Kong $N$, Werb Z. The cancer stem cell niche: how essential is the niche in regulating stemness of tumor cells? Cell Stem Cell. 2015;16(3):22538.

54. Yu H, Lee H, Herrmann A, Buettner R, Jove R. Revisiting STAT3 signalling in cancer: new and unexpected biological functions. Nat Rev Cancer. 2014; 14(11):736-46.

55. Tao W, Chu C, Zhou W, et al. Dual role of WISP1 in maintaining glioma stem cells and tumor-supportive macrophages in glioblastoma. Nat Commun. 2020;11(1):3015.

56. Uehara I, Tanaka N. Role of p53 in the regulation of the inflammatory tumor microenvironment and tumor suppression. Cancers (Basel). 2018;10(7):219.

57. Lu Z, Zou J, Li S, et al. Epigenetic therapy inhibits metastases by disrupting premetastatic niches. Nature. 2020;579(7798):284-90.

58. Kitamura T, Qian BZ, Pollard JW. Immune cell promotion of metastasis. Nat Rev Immunol. 2015;15(2):73-86.

59. Liu Y, Cao X. Immunosuppressive cells in tumor immune escape and metastasis. J Mol Med (Berl). 2016;94(5):509-22.

60. Tan HX, Gong WZ, Zhou K, et al. CXCR4/TGF- $\beta 1$ mediated hepatic stellate cells differentiation into carcinoma-associated fibroblasts and promoted liver metastasis of colon cancer. Cancer Biol Ther. 2020;21(3):258-68.

61. Du L, Han XG, Tu B, et al. CXCR1/Akt signaling activation induced by mesenchymal stem cell-derived IL-8 promotes osteosarcoma cell anoikis resistance and pulmonary metastasis. Cell Death Dis. 2018;9(7):714.

62. Facciabene A, Peng X, Hagemann IS, et al. Tumour hypoxia promotes tolerance and angiogenesis via CCL28 and T(reg) cells. Nature. 2011; 475(7355):226-30

63. Corzo CA, Condamine T, Lu L, et al. HIF-1a regulates function and differentiation of myeloid-derived suppressor cells in the tumor microenvironment. J Exp Med. 2010;207(11):2439-53.

64. Li M, Qi Y, Chen $M$, et al. GATA binding protein 3 boosts extracellular ATP hydrolysis and inhibits metastasis of breast Cancer by up-regulating Ectonucleoside triphosphate Diphosphohydrolase 3. Int J Biol Sci. 2019; 15(12):2522-37.

65. Jiang LH, Mousawi F, Yang X, Roger S. ATP-induced Ca2+-signalling mechanisms in the regulation of mesenchymal stem cell migration. Cell Mol Life Sci. 2017;74(20):3697-710.

66. Neophytou CM, Kyriakou TC, Papageorgis P. Mechanisms of metastatic tumor dormancy and implications for Cancer therapy. Int J Mol Sci. 2019;20(24):6158.

67. Milette S, Sicklick JK, Lowy AM, Brodt P. Molecular pathways: targeting the microenvironment of liver metastases. Clin Cancer Res. 2017:23(21):6390-9.

68. Pein M, Insua-Rodríguez J, Hongu T, et al. Metastasis-initiating cells induce and exploit a fibroblast niche to fuel malignant colonization of the lungs. Nat Commun. 2020;11(1):1494.

69. Li Q, Zhu CC, Ni B, et al. Lysyl oxidase promotes liver metastasis of gastric cancer via facilitating the reciprocal interactions between tumor cells and cancer associated fibroblasts. EBioMedicine. 2019:49:157-71.

70. Vander Heiden MG, Cantley LC, Thompson CB. Understanding the Warburg effect: the metabolic requirements of cell proliferation. Science. 2009; 324(5930):1029-33. 
71. Yang $L$, Achreja A, Yeung $T L$, et al. Targeting stromal glutamine Synthetase in tumors disrupts tumor microenvironment-regulated Cancer cell growth. Cell Metab. 2016;24(5):685-700.

72. Meads MB, Gatenby RA, Dalton WS. Environment-mediated drug resistance: a major contributor to minimal residual disease. Nat Rev Cancer. 2009;9(9): 665-74.

73. Heldin $\mathrm{CH}$, Rubin K, Pietras K, Ostman A. High interstitial fluid pressure - an obstacle in cancer therapy. Nat Rev Cancer. 2004;4(10):806-13.

74. Kaplan RN, Riba RD, Zacharoulis S, et al. VEGFR1-positive haematopoietic bone marrow progenitors initiate the pre-metastatic niche. Nature. 2005; 438(7069):820-7.

75. Gao H, Chakraborty G, Lee-Lim AP, et al. The BMP inhibitor coco reactivates breast cancer cells at lung metastatic sites. Cell. 2012;150(4):764-79.

76. Yoshikawa K, Mitsunaga S, Kinoshita T, et al. Impact of tumor-associated macrophages on invasive ductal carcinoma of the pancreas head. Cancer Sci. 2012;103(11):2012-20.

77. Wu T, Dai Y. Tumor microenvironment and therapeutic response. Cancer Lett. 2017;387:61-8.

78. Margolin DA, Silinsky J, Grimes C, et al. Lymph node stromal cells enhance drug-resistant colon cancer cell tumor formation through SDF-1a/CXCR4 paracrine signaling. Neoplasia. 2011;13(9):874-86.

79. Zigrino P, Nischt R, Mauch C. The disintegrin-like and cysteine-rich domains of ADAM-9 mediate interactions between melanoma cells and fibroblasts. J Biol Chem. 2011;286(8):6801-7.

80. Bruchard M, Mignot $G$, Derangère $V$, et al. Chemotherapy-triggered cathepsin B release in myeloid-derived suppressor cells activates the Nlrp3 inflammasome and promotes tumor growth. Nat Med. 2013;19(1):57-64.

81. Höpken UE, Rehm A. Homeostatic chemokines guide lymphoma cells to tumor growth-promoting niches within secondary lymphoid organs. J Mol Med (Berl). 2012;90(11):1237-45.

82. Ten Hacken E, Burger JA. Microenvironment interactions and B-cell receptor signaling in chronic lymphocytic leukemia: implications for disease pathogenesis and treatment. Biochim Biophys Acta. 2016;1863(3):401-13.

83. Höpken UE, Rehm A. Targeting the tumor microenvironment of leukemia and lymphoma. Trends Cancer. 2019;5(6):351-64.

84. Müller G, Höpken UE, Lipp M. The impact of CCR7 and CXCR5 on lymphoid organ development and systemic immunity. Immunol Rev. 2003;195:117-35.

85. Fowler NH, Nastoupil $L$, Hagemeister FB, et al. Characteristics and management of rash following lenalidomide and rituximab in patients with untreated indolent non-Hodgkin lymphoma. Haematologica. 2015;100(11): e454-7.

86. Galluzzi L, Buqué A, Kepp O, Zitvogel L, Kroemer G. Immunological effects of conventional chemotherapy and targeted anticancer agents. Cancer Cell. 2015;28(6):690-714.

87. Zitvogel L, Galluzzi L, Smyth MJ, Kroemer G. Mechanism of action of conventional and targeted anticancer therapies: reinstating immunosurveillance. Immunity. 2013;39(1):74-88

88. Gotwals P, Cameron S, Cipolletta D, et al. Prospects for combining targeted and conventional cancer therapy with immunotherapy. Nat Rev Cancer. 2017; 17(5):286-301.

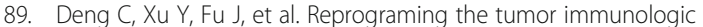
microenvironment using neoadjuvant chemotherapy in osteosarcoma. Cancer Sci. 2020;111(6):1899-909.

90. Winterhoff B, Freyer L, Hammond E, et al. PG545 enhances anti-cancer activity of chemotherapy in ovarian models and increases surrogate biomarkers such as VEGF in preclinical and clinical plasma samples. Eur J Cancer. 2015;51(7):879-92.

91. Aiello NM, Bajor DL, Norgard RJ, et al. Metastatic progression is associated with dynamic changes in the local microenvironment. Nat Commun. 2016; 7:12819.

92. Xing F, Liu Y, Wu SY, et al. Loss of XIST in breast Cancer activates MSN-C met and reprograms microglia via Exosomal miRNA to promote brain metastasis. Cancer Res. 2018;78(15):4316-30

93. Karagiannis GS, Condeelis JS, Oktay MH. Chemotherapy-induced metastasis: molecular mechanisms, clinical manifestations, Therapeutic Interventions. Cancer Res. 2019;79(18):4567-76.

94. Shao LN, Zhu BS, Xing CG, Yang XD, Young W, Cao JP. Effects of autophagy regulation of tumor-associated macrophages on radiosensitivity of colorectal cancer cells. Mol Med Rep. 2016;13(3):2661-70.

95. Yang C, Qin S. Apatinib targets both tumor and endothelial cells in hepatocellular carcinoma. Cancer Med. 2018;7(9):4570-83.
96. Grither WR, Longmore GD. Inhibition of tumor-microenvironment interaction and tumor invasion by small-molecule allosteric inhibitor of DDR2 extracellular domain. Proc Natl Acad Sci U S A. 2018;115(33):E778694.

97. Lee HM, Lee E, Yeo SY, et al. Drug repurposing screening identifies bortezomib and panobinostat as drugs targeting cancer associated fibroblasts (CAFs) by synergistic induction of apoptosis. Investig New Drugs. 2018;36(4):545-60.

98. Takigawa H, Kitadai Y, Shinagawa K, et al. Multikinase inhibitor regorafenib inhibits the growth and metastasis of colon cancer with abundant stroma. Cancer Sci. 2016;107(5):601-8.

99. Wei SC, Duffy CR, Allison JP. Fundamental mechanisms of immune checkpoint blockade therapy. Cancer Discov. 2018;8(9):1069-86.

100. Zhang $P$, Xiong $X$, Rolfo $C$, et al. Mechanism- and immune landscape-based ranking of therapeutic responsiveness of 22 major human cancers to next generation anti-CTLA-4 antibodies. Cancers (Basel). 2020;12(2):284

101. Liu Y, Zheng P. Preserving the CTLA-4 checkpoint for safer and more effective Cancer immunotherapy. Trends Pharmacol Sci. 2020;41(1):4-12.

102. Poggio M, Hu T, Pai CC, et al. Suppression of Exosomal PD-L1 Induces Systemic Anti-tumor Immunity and Memory. Cell. 2019;177(2):414-427.e13.

103. Tauriello DVF, Palomo-Ponce $S$, Stork $D$, et al. TGF $\beta$ drives immune evasion in genetically reconstituted colon cancer metastasis. Nature. 2018;554(7693): $538-43$.

104. Xu X, Ho W, Zhang X, Bertrand N, Farokhzad O. Cancer nanomedicine: from targeted delivery to combination therapy. Trends Mol Med. 2015;21(4):22332.

105. Shi D, Bedford NM, Cho HS. Engineered multifunctional nanocarriers for cancer diagnosis and therapeutics. Small. 2011;7(18):2549-67.

106. Zhang F, Stephan SB, Ene Cl, Smith TT, Holland EC, Stephan MT. Nanoparticles that reshape the tumor milieu create a therapeutic window for effective T-cell therapy in solid malignancies. Cancer Res. 2018;78(13): 3718-30.

107. Jiang T, Chen L, Huang Y, et al. Metformin and Docosahexaenoic acid hybrid micelles for Premetastatic niche modulation and tumor metastasis suppression. Nano Lett. 2019;19(6):3548-62.

108. Chen B, Dai W, Mei D, et al. Comprehensively priming the tumor microenvironment by cancer-associated fibroblast-targeted liposomes for combined therapy with cancer cell-targeted chemotherapeutic drug delivery system. J Control Release. 2016;241:68-80.

109. Zhen Z, Tang W, Wang M, et al. Protein Nanocage mediated fibroblastactivation protein targeted Photoimmunotherapy to enhance cytotoxic T cell infiltration and tumor control. Nano Lett. 2017;17(2):862-9.

110. Lin $Y G$, Kunnumakkara $A B$, Nair $A$, et al. Curcumin inhibits tumor growth and angiogenesis in ovarian carcinoma by targeting the nuclear factorkappaB pathway. Clin Cancer Res. 2007;13(11):3423-30.

111. Bao B, Ali S, Ahmad A, et al. Hypoxia-induced aggressiveness of pancreatic cancer cells is due to increased expression of VEGF, IL-6 and miR-21, which can be attenuated by CDF treatment. PLoS One. 2012;7(12):e50165.

112. Basak SK, Bera A, Yoon AJ, et al. A randomized, phase 1, placebo-controlled trial of APG-157 in oral cancer demonstrates systemic absorption and an inhibitory effect on cytokines and tumor-associated microbes. Cancer. 2020;126(8):1668-82.

113. Choi YH, Han DH, Kim SW, et al. A randomized, double-blind, placebocontrolled trial to evaluate the role of curcumin in prostate cancer patients with intermittent androgen deprivation. Prostate. 2019;79(6):614-21.

114. Zhuang $H$, Dai $X$, Zhang $X$, Mao Z, Huang $H$. Sophoridine suppresses macrophage-mediated immunosuppression through TLR4/IRF3 pathway and subsequently upregulates CD8+ T cytotoxic function against gastric cancer. Biomed Pharmacother. 2020;121:109636

115. Li H, Huang N, Zhu W, et al. Modulation the crosstalk between tumorassociated macrophages and non-small cell lung cancer to inhibit tumor migration and invasion by ginsenoside Rh2. BMC Cancer. 2018;18(1):579.

116. Huang C, Wang XL, Qi FF, Pang ZL. Berberine inhibits epithelialmesenchymal transition and promotes apoptosis of tumour-associated fibroblast-induced colonic epithelial cells through regulation of TGF- $\beta$ signalling. J Cell Commun Signal. 2020;14(1):53-66.

117. Li M, Yue GG, Song LH, et al. Natural small molecule bigelovin suppresses orthotopic colorectal tumor growth and inhibits colorectal cancer metastasis via IL6/STAT3 pathway. Biochem Pharmacol. 2018;150:191-201.

118. Jin Y, Meng X, Qiu Z, Su Y, Yu P, Qu P. Anti-tumor and anti-metastatic roles of cordycepin, one bioactive compound of Cordyceps militaris. Saudi J Biol Sci. 2018;25(5):991-5. 
119. Wei Y, Li M, Cui S, et al. Shikonin inhibits the proliferation of human breast Cancer cells by reducing tumor-derived Exosomes. Molecules. 2016;21(6): 777.

120. Sun C, Fang Y, Yin J, et al. Rational combination therapy with PARP and MEK inhibitors capitalizes on therapeutic liabilities in RAS mutant cancers. Sci Transl Med. 2017:9(392):eaal5148.

121. Lord CJ, Ashworth A. PARP inhibitors: synthetic lethality in the clinic. Science. 2017;355(6330):1152-8.

122. Guo S, Lin CM, Xu Z, Miao L, Wang Y, Huang L. Co-delivery of cisplatin and rapamycin for enhanced anticancer therapy through synergistic effects and microenvironment modulation. ACS Nano. 2014;8:4996-5009.

123. Jiao S, Xia W, Yamaguchi H, et al. PARP inhibitor Upregulates PD-L1 expression and enhances Cancer-associated immunosuppression. Clin Cancer Res. 2017;23(14):3711-20.

124. Reisländer T, Lombardi EP, Groelly FJ, et al. BRCA2 abrogation triggers innate immune responses potentiated by treatment with PARP inhibitors. Nat Commun. 2019;10(1):3143.

125. Gou HF, Zhou L, Huang J, Chen XC. Intraperitoneal oxaliplatin administration inhibits the tumor immunosuppressive microenvironment in an abdominal implantation model of colon cancer. Mol Med Rep. 2018; 18(2):2335-41.

126. Zheng B, Ren T, Huang Y, Guo W. Apatinib inhibits migration and invasion as well as PD-L1 expression in osteosarcoma by targeting STAT3. Biochem Biophys Res Commun. 2018;495(2):1695-701.

127. Huang M, Huang B, Li G, Zeng S. Apatinib affect VEGF-mediated cell proliferation, migration, invasion via blocking VEGFR2/RAF/MEK/ERK and PI3K AKT pathways in cholangiocarcinoma cell. BMC Gastroenterol. 2018; 18(1):169.

128. Uribesalgo I, Hoffmann D, Zhang Y, et al. Apelin inhibition prevents resistance and metastasis associated with anti-angiogenic therapy. EMBO Mol Med. 2019;11(8):e9266.

129. Hadla M, Palazzolo S, Corona G, et al. Exosomes increase the therapeutic index of doxorubicin in breast and ovarian cancer mouse models. Nanomedicine (Lond). 2016;11(18):2431-41.

130. Li Y, Gao Y, Gong C, et al. A33 antibody-functionalized exosomes for targeted delivery of doxorubicin against colorectal cancer. Nanomedicine. 2018;14(7):1973-85.

131. Sternberg C, Armstrong A, Pili R, et al. Randomized, double-blind, placebocontrolled phase III study of Tasquinimod in men with metastatic castration-resistant prostate Cancer. J Clin Oncol. 2016;34(22):2636-43.

132. Karasaki T, Nagayama K, Kuwano H, et al. An Immunogram for the Cancerimmunity cycle: towards personalized immunotherapy of lung Cancer. J Thorac Oncol. 2017;12(5):791-803.

133. Mariathasan S, Turley SJ, Nickles D, et al. TGF $\beta$ attenuates tumour response to PD-L1 blockade by contributing to exclusion of T cells. Nature. 2018; 554(7693):544-8.

134. Gravina GL, Mancini A, Muzi P, et al. CXCR4 pharmacogical inhibition reduces bone and soft tissue metastatic burden by affecting tumor growth and tumorigenic potential in prostate cancer preclinical models. Prostate. 2015;75(12):1227-46

135. Georgoudaki AM, Prokopec KE, Boura VF, et al. Reprogramming tumorassociated macrophages by antibody targeting inhibits Cancer progression and metastasis. Cell Rep. 2016:15(9):2000-11.

136. Marsh JL, Jackman CP, Tang SN, Shankar S, Srivastava RK. Embelin suppresses pancreatic cancer growth by modulating tumor immune microenvironment. Front Biosci (Landmark Ed). 2014;19:113-25.

137. Jeffery JJ, Lux K, Vogel JS, et al. Autocrine inhibition of the c-fms protooncogene reduces breast cancer bone metastasis assessed with in vivo dual-modality imaging. Exp Biol Med (Maywood). 2014;239(4):404-13.

138. Emens LA. Breast Cancer immunotherapy: facts and hopes. Clin Cancer Res. 2018;24(3):511-20

139. Savas $P$, Salgado $R$, Denkert $C$, et al. Clinical relevance of host immunity in breast cancer: from TILs to the clinic. Nat Rev Clin Oncol. 2016;13(4):228-41.

140. Cimino-Mathews A, Thompson E, Taube JM, et al. PD-L1 (B7-H1) expression and the immune tumor microenvironment in primary and metastatic breast carcinomas. Hum Pathol. 2016:47(1):52-63.

141. Li X, Li M, Lian Z, et al. Prognostic role of programmed death Ligand-1 expression in breast Cancer: a systematic review and meta-analysis. Target Oncol. 2016;11(6):753-61.

142. Tokito T, Azuma K, Kawahara A, et al. Predictive relevance of PD-L1 expression combined with CD8+ TIL density in stage III non-small cell lung cancer patients receiving concurrent chemoradiotherapy. Eur J Cancer. 2016:55:7-14.

143. Matsushita H, Sato Y, Karasaki T, et al. Neoantigen load, antigen presentation machinery, and immune signatures determine prognosis in clear cell renal cell carcinoma. Cancer Immunol Res. 2016;4(5):463-71.

144. Taube JM, Young GD, McMiller TL, et al. Differential expression of immuneregulatory genes associated with PD-L1 display in melanoma: implications for PD-1 pathway blockade. Clin Cancer Res. 2015;21(17):3969-76.

145. Liu M, Song W, Huang L. Drug delivery systems targeting tumor-associated fibroblasts for cancer immunotherapy. Cancer Lett. 2019;448:31-9.

146. Zhou L, Wang H, Li Y. Stimuli-responsive Nanomedicines for overcoming Cancer multidrug resistance. Theranostics. 2018;8(4):1059-74.

147. Wan G, Chen B, Li L, et al. Nanoscaled red blood cells facilitate breast cancer treatment by combining photothermal/photodynamic therapy and chemotherapy [published correction appears in biomaterials. Biomaterials. 2018;155:25-40

148. Uthaman S, Huh KM, Park IK. Tumor microenvironment-responsive nanoparticles for cancer theragnostic applications. Biomater Res. 2018;22:22.

149. Sun T, Zhang YS, Pang B, Hyun DC, Yang M, Xia Y. Engineered nanoparticles for drug delivery in cancer therapy. Angew Chem Int Ed Engl. 2014;53(46): 12320-64.

150. Din FU, Aman W, Ullah I, et al. Effective use of nanocarriers as drug delivery systems for the treatment of selected tumors. Int J Nanomedicine. 2017;12: 7291-309.

151. Zhang T, Liu H, Li Y, et al. A pH-sensitive nanotherapeutic system based on a marine sulfated polysaccharide for the treatment of metastatic breast cancer through combining chemotherapy and COX-2 inhibition. Acta Biomater. 2019;99:412-25.

152. Wilken R, Veena MS, Wang MB, Srivatsan ES. Curcumin: a review of anticancer properties and therapeutic activity in head and neck squamous cell carcinoma. Mol Cancer. 2011;10:12

153. Zhao Y, Yao J, Wu XP, et al. Wogonin suppresses human alveolar adenocarcinoma cell A549 migration in inflammatory microenvironment by modulating the IL-6/STAT3 signaling pathway. Mol Carcinog. 2015;54(Suppl 1):E81-93.

154. Liu H, Shen M, Zhao D, et al. The effect of Triptolide-loaded Exosomes on the proliferation and apoptosis of human ovarian Cancer SKOV3 cells. Biomed Res Int. 2019;2019:2595801.

155. Zhong W, Yang W, Qin Y, et al. 6-Gingerol stabilized the p-VEGFR2NEcadherin/ $\beta$-catenin/actin complex promotes microvessel normalization and suppresses tumor progression. J Exp Clin Cancer Res. 2019;38(1):285.

156. Yang Y, Zhang L, La X, Li Z, Li H, Guo S. Salvianolic acid a inhibits tumorassociated angiogenesis by blocking GRP78 secretion. Naunyn Schmiedeberg's Arch Pharmacol. 2019;392(4):467-80.

157. Zhuang M, Xin G, Wei Z, et al. Dihydrodiosgenin inhibits endothelial cellderived factor VIII and platelet-mediated hepatocellular carcinoma metastasis. Cancer Manag Res. 2019:11:4871-82.

158. Heeren AM, van Luijk IF, Lakeman J, et al. Neoadjuvant cisplatin and paclitaxel modulate tumor-infiltrating $T$ cells in patients with cervical cancer. Cancer Immunol Immunother. 2019;68(11):1759-67.

159. Kitano H, Kitadai $Y$, Teishima J, et al. Combination therapy using moleculartargeted drugs modulates tumor microenvironment and impairs tumor growth in renal cell carcinoma. Cancer Med. 2017:6(10):2308-20.

160. Iwamoto $H$, Abe M, Yang Y, et al. Cancer Lipid Metabolism Confers Antiangiogenic Drug Resistance. Cell Metab. 2018;28(1):104-117.e5.

161. Ashworth A, Lord CJ, Reis-Filho JS. Genetic interactions in cancer progression and treatment. Cell. 2011;145(1):30-8.

162. Golan T, Hammel P, Reni M, et al. Maintenance Olaparib for Germline BRCAmutated metastatic pancreatic Cancer. N Engl J Med. 2019;381(4):317-27.

163. Howells LM, Iwuji COO, Irving GRB, et al. Curcumin combined with FOLFOX chemotherapy is safe and tolerable in patients with metastatic colorectal Cancer in a randomized phase lla trial. J Nutr. 2019;149(7):1133-9.

164. Sheng X, Sun X, Sun K, Sui H, Qin J, Li Q. Inhibitory effect of bufalin combined with hedgehog signaling pathway inhibitors on proliferation and invasion and metastasis of liver cancer cells. Int J Oncol. 2016;49(4):1513-24.

165. Wang H, Zhang C, Chi H, Meng Z. Synergistic anti-hepatoma effect of bufalin combined with sorafenib via mediating the tumor vascular microenvironment by targeting mTOR/NEGF signaling. Int J Oncol. 2018;52(6):2051-60.

166. Wang J, Tian L, Khan MN, et al. Ginsenoside Rg3 sensitizes hypoxic lung cancer cells to cisplatin via blocking of NF-KB mediated epithelialmesenchymal transition and stemness. Cancer Lett. 2018;415:73-85. 
167. Pang N, Li J, Sun A, Yang Z, Cheng S, Qi XR. Prior anti-CAFs break down the CAFs barrier and improve accumulation of docetaxel micelles in tumor. Int $J$ Nanomedicine. 2018;13:5971-90.

\section{Publisher's Note}

Springer Nature remains neutral with regard to jurisdictional claims in published maps and institutional affiliations.

Ready to submit your research? Choose BMC and benefit from:

- fast, convenient online submission

- thorough peer review by experienced researchers in your field

- rapid publication on acceptance

- support for research data, including large and complex data types

- gold Open Access which fosters wider collaboration and increased citations

- maximum visibility for your research: over $100 \mathrm{M}$ website views per year

At $\mathrm{BMC}$, research is always in progress. 